Discussion Paper No. 16-066

\title{
Evaluation of Best Price Clauses in Hotel Booking
}

Matthias Hunold, Ulrich Laitenberger, and Frank Schlütter

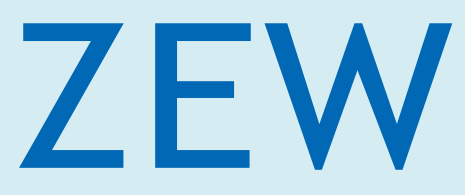

Zentrum für Europäische Wirtschaftsforschung $\mathrm{GmbH}$ Centre for European Economic Research 
Discussion Paper No. 16-066

\title{
Evaluation of Best Price Clauses in Hotel Booking
}

\author{
Matthias Hunold, Ulrich Laitenberger, \\ and Frank Schlütter
}

Download this ZEW Discussion Paper from our ftp server:

http://ftp.zew.de/pub/zew-docs/dp/dp16066.pdf

Die Discussion Papers dienen einer möglichst schnellen Verbreitung von neueren Forschungsarbeiten des ZEW. Die Beiträge liegen in alleiniger Verantwortung der Autoren und stellen nicht notwendigerweise die Meinung des ZEW dar.

Discussion Papers are intended to make results of ZEW research promptly available to other economists in order to encourage discussion and suggestions for revisions. The authors are solely responsible for the contents which do not necessarily represent the opinion of the ZEW. 


\title{
Evaluation of best price clauses in hotel booking
}

\author{
Matthias Hunold, ${ }^{*}$ Ulrich Laitenberger ${ }^{\dagger}$ and Frank Schlütter ${ }^{\ddagger}$
}

October 7, 2016

\begin{abstract}
We analyze the best price clauses (BPCs) of online travel agents (OTAs) using meta-search price data of more than 45,000 hotels in different countries. Although OTAs apparently have not changed their standard commission rates following the partial ban of BPCs in Europe, we find that BPCs do influence the pricing and availability of hotel rooms across online sales channels. In particular, the abolition of Booking.com's narrow BPC is associated with the hotels' direct channel being the price leader more often. Moreover, hotels make rooms more often available at Booking.com when it does not use the narrow BPC.
\end{abstract}

Keywords: Best price clauses, hotel booking, MFN, OTA, vertical restraints. JEL Class: D40, L42, L81

${ }^{*}$ Heinrich Heine Universität (HHU) Düsseldorf, Düsseldorf Institute for Competition Economics (DICE), Universitätsstr. 1, 40225 Düsseldorf, Germany; e-mail: hunold@dice.hhu.de.

†ZEW Centre for European Economic Research, MaCCI Mannheim Centre for Competition and Innovation, Address: L7,1, 68161 Mannheim, Germany; E-mail: laitenberger@zew.de.

Affiliated researcher - KU Leuven, Department of Managerial Economics, Strategy and Innovation, Naamsestraat 69, 3000 Leuven, Belgium.

${ }^{\ddagger}$ DICE as above; e-mail: frank.schluetter@outlook.de.

Financial support by the State Government of Baden-Württemberg, Germany, through the research program 'Strengthening Efficiency and Competitiveness in the European Knowledge Economies' (SEEK) is gratefully acknowledged.

We thank participants at the ICT Conference in Mannheim 2016, seminar participants at the University of Cologne, and in particular Irene Bertschek, Justin Johnson, Michael Kummer and Martin Peitz for helpful comments. 


\section{Introduction}

Motivated by recent proceedings against best price clauses (BPC) imposed by online travel agents (OTA), we empirically investigate the effects of such clauses using metasearch price data of more than 45,000 hotels in various countries ${ }^{1}$ Under a BPC, an OTA obliges the hotel not to charge a higher price on the OTA than on certain other channels. The NCAs in Europe generally agreed that best price clauses could restrict competition between OTAs for commission rates, but eventually arrived at different assessments and decisions $:^{2}$ These differences trigger the question how BPCs actually affect the market outcome. The theoretical literature on this topic is indeed evolving rapidly. While several articles predict impeded OTA competition and an inflated price level for wide BPCs (Johnson (2014) and Boik and Corts (2016)), others find ambiguous effects of narrow BPCs (Edelman and Wright (2015) and Wang and Wright (2015)). In contrast to the theoretical research on this topic, the empirical research is very limited. With this article we start to fill the gap.

We use the variation in the BPCs due to different national enforcement policies across various countries and over time. The different decisions of the European competition authorities seem to be rather due to differences in their assessments than to fundamental differences in the market characteristics in each country (see Hunold (2016)). For instance, the French competition authority had accepted Booking.com's commitments to narrow down the parity clauses in April 2015, just to be overruled by the French parliament that completely prohibited BPCs of OTAs in France in July 2015. These different decisions provide a quasi-experimental setup for assessing the effects of different BPC policies.

As prohibitions of BPCs generally aim at enhancing OTA competition, one would expect to observe changes in the commission rates that hotels have to pay to the OTA for every mediated booking. However, according to our research, the standard commission rates of the major OTAs have not changed since the competition policy interventions in Europe $3^{3}$ Therefore, we focus in this article on the effects of BPCs on the hotels' choices of price

\footnotetext{
${ }^{1}$ In this article, we generally refer to hotels as the typical accommodations on offer at a booking platform. In its general terms and conditions, Booking.com uses the term "accommodation". Other types of accommodation present on OTAs include, for example, holiday apartments.

${ }^{2}$ See Annex IV for a list of the different decisions.

${ }^{3}$ See Annex III for details.
} 
publications and levels across OTAs and the hotels' direct online channel.

We use data on prices of hotel rooms on different online sales channels of the period January to July 2016 collected from Kayak. $4^{4}$ Kayak is a meta travel search engine that collects information from various online channels such as the OTAs Booking.com, Expedia and the direct online hotel channels. Our empirical approach is twofold: First, we point out a set of interesting observations in relation to channel choice and pricing decisions across channels by means of cross sectional statistics. Second, we exploit the variation over time to identify the effects of the narrow BPCs by means of a difference-in-differences approach. We use the fact that Booking.com is prohibited to use its narrow BPCs in Germany since February 2016.5 We therefore compare the changes in the market outcome in Germany with the changes in other countries without such a change in the relevant time frame. For this, we use regression analyses to control for possibly confounding factors. Our identifying assumption in this case is that there are no other country specific developments since January 2016 - except for the ones which we can control for, such as the utilization rates of hotels at the city level.

With respect to the price structure across sales channels, we find that hotels set the price at the direct channel lower than at the largest OTA Booking.com in about one third of our observations across all BPC regimes. Nevertheless, the data suggest that especially the wide $\mathrm{BPC}$ is effective in constraining price dispersion across sales channels to some extent. The finding of lower direct channel prices suggest a wide-spread non-compliance with the price parity clause and is important for both conceptual work and competition policy. If one out of three hotels does not comply with the BPCs, this is likely to reduce the possible anti-competitive effects of BPCs compared to a situation where all hotels comply. At the same time the result indicates a strong incentive for hotels to attract direct channel bookings, which can be assumed to typically have the lowest marginal costs for hotels.

We find an increased channel use which can be attributed to the abolition of Booking.com's narrow BPC in Germany. We observe that more hotels start using Booking.com as a dis-

\footnotetext{
${ }^{4}$ We use the German edition of the internet site www.kayak.de. Since 2013, Kayak is a subsidiary of the Priceline Group, which previously also acquired the online travel agencies Booking.com (2004) and Agoda.com (2007).

${ }^{5}$ See Subsection 2.2 for a precise definition of wide and narrow BPCs and Annex IV for an overview of the decisions.
} 
tribution channel (extensive use) after it had to remove the price parity and minimum availability clauses in relation to the direct channel in Germany, when compared to the developments in other countries. This result suggests that a fraction of the hotels does indeed respond flexibly to parity clauses by not being active at an OTA imposing them. The fraction of previously inactive hotels had apparently not been large enough for Booking.com to prefer to not use a BPC. The increase in hotels using a narrow BPC should nevertheless now benefit Booking.com as a side effect of the narrow BPC prohibition. Moreover, we also observe an increased use of the direct online channel (intensive use) which indicates that hotels find it increasingly attractive to use this channel since it is no more constrained by Booking.com's narrow BPC.

With respect to the adjustment process after the abolition of Booking.com's narrow BPC in Germany, our difference-in-differences approach reveals that hotels are able to establish the direct channel more frequently as the cheaper channel relative to the major OTAs and also more frequently as the price leader in the sense of the cheapest channel across all available online sales channels. This lets us conclude that Booking.com's narrow BPC did restrict the hotel's price setting. It contributes to the discussion of whether there is a free-riding problem in that hotels might use the OTAs to show their rooms but induce customers with lower prices to eventually book directly.

In two instances we observe a similar development as for Booking.com in Germany after the abolition of its narrow BPC. First, the price relation between Expedia and the direct channel evolves similarly to the relation between Booking.com and the direct channel in Germany, despite the fact that Expedia still has its narrow BPC in place. This development indicates an increasing non-compliance with Expedia's price parity. Second, with regard to the publication decisions and the price leadership of the direct channel, we find for Austria a time trend that is not significantly different or even stronger than in Germany. Like for Expedia in Germany, we understand that Booking.com and Expedia still use narrow BPCs in Austria. However, the German competition authority (Bundeskartellamt) is apparently still investigating the narrow BPC of Expedia and also Austria is further proceeding against narrow BPCs of OTAs. Therefore, we conclude that hotels anticipate prohibitions of these BPCs and that enforcement of these clauses becomes more difficult for Expedia in Germany and for both Booking.com and Expedia 
in Austria.

The remainder of the article is structured as follows. We discuss the related literature in the next section, provide background information about OTAs, BPCs and competition policy in Section 3 , introduce the data in Section 4 , discuss conjectures, methodology and identification in Section 5 , the analysis of price publications across channels in Section 6 , the pricing analysis in Section 7, and then conclude in Section 8 .

\section{Related literature}

\subsection{Theory in relation to BPCs}

The theory of harm with respect to wide BPCs is generally supported by recent theoretical research. Boik and Corts (2016) and Johnson (2014) analyze BPCs in a model in which customers can only purchase through a platform and in which platforms compete in revenue-sharing contracts. Boik and Corts (2016) show that BPCs lead to an increase in retail prices and platform fees. Moreover, higher platform profits may raise incentives for potential entrants, but market entry of lower-cost, lower-value platforms is exacerbated due to price parity and therefore BPCs also impose a large obstacle on market entry. Johnson (2014) investigates the difference between the agency model, where hotels set prices through the platform and pay a commission for every transaction, and the merchant model, where the platform acts as retailer of hotel rooms. While Johnson (2014) finds a neutral effect of BPCs in the wholesale model, he shows that BPCs adopted in the agency model result in higher retail prices, lower hotel's profits and a maximization of platform's profits. He also shows that BPCs tend to endogenously emerge in the agency model.

Edelman and Wright (2015) and Wang and Wright (2015) assume that platforms charge linear per-transaction fees and allow customers to buy from either the platform or the direct channel. Edelman and Wright (2015) refer to BPCs as price coherence and find incentives for excessive investment in convenience benefits. This leads to even higher prices and negative "externalities on nontraders" in line with Segal (1999), i.e. consumers who do not use the platform are harmed by price parity, due to a higher price level. Wang and Wright (2015) expand the setting by allowing the customers to search on the 
platform and switch the sales channel to complete the transaction. To our knowledge they are the first who allow for the possibility that consumers search on OTAs and then book at a lower price on the direct channel. This allows them to address an important aspect in the ongoing discussion of the competitive effects of narrow BPC. They show that showrooming effectively disciplines the platforms' incentives to raise commissions, but may make platforms unviable - depending on its marginal costs and the extent of convenience benefits that the platform offers to the customers.

\subsection{Empirical literature in relation to OTAs}

As discussed above, there is sound economic theory that BPCs of OTAs have the potential to restrict competition among OTAs for commission rates and deter entry. Yet, it remains an empirical question whether and - if yes - by how much the wide and narrow BPCs of OTAs affect the market outcome. However, to our knowledge, there are not yet any research articles available which address this question. There is though related research that investigates i) the pricing at online marketplaces, and ii) search behavior of consumers on platforms such as OTAs.

Several articles study online prices of various goods and services (Brynjolfsson and Smith (2000), Clemons et al. (2002), Chellappa et al. (2011) Gorodnichenko et al. (2014) and Kaplan et al. (2016)). They find that online prices are often lower and adjusted more frequently than offline prices. Moreover, online prices exhibit considerable price dispersion. Ghose and Yao (2011) and Zhao et al. (2015) compare list prices with transaction prices and find that price dispersion is prevalent in both, but less so in transaction prices. Our work is related in that we also find considerable dispersion of hotel room prices online.

More closely related are Lu et al. (2015) who study the relationship between the pricing of intermediaries, such as physical travel agents, and the introduction of a new online direct sales channel of a hotel chain. Using data of hotel room transactions from 2001 to 2007, they analyze the introduction of the direct online sales channel in 2002 and find a significant reduction of the intermediaries' price premia. This result suggests that there is competition between different form of sales channels for hotel distribution. However, Lu et al. do not study BPCs. 
Another stream of empirical literature seeks to explain consumer's search behavior of OTAs and the role of their hotel rankings. Ursu (2015) exploiting a random variation in the ranking of the OTA Expedia studies the effect of rankings on search and booking behavior. She finds direct effects of rankings on search costs and that better ranking positions are associated with more clicks on the particular offer, i.e. the higher an offer is ranked the higher is the probability that customers click on the offer in order to obtain detailed information on this offer. However, she finds that once a customer has clicked on an offer, the probability for a booking is not influenced by the ranking position. Ghose et al. (2012) also stress that ranking quality has a large impact on search costs and has an increasing importance due to social media overload. They propose a structural model in order to predict consumers' online search paths and thereby improve search engine performance. In the context of hotel room booking they find that a high quality ranking can save customers (in money equivalents) up to 9.38 USD per hotel booking. In general, these results highlight the importance of intermediary services in hotel online distribution as provided by OTAs. In the following section we point out recent developments of the hotel online market and introduce the analysis in the subsequent sections.

\section{$3 \quad$ Background information on online hotel booking}

\subsection{Market development}

With the emergence of OTAs, hotel distribution has increasingly shifted to online market places (Buhalis and Law (2008)). The importance of traditional offline sales channels such as bookings via walk-ins or via telephone is declining correspondingly. As the advance of information and communication technology has resulted in an increasingly complex array of intermediaries (Kracht and Wang (2010)), this shift is accompanied by a general trend to less bookings via the hotels' direct offline channels to a more extensive use of intermediary services offered e.g. from OTAs or meta-search engines. In recent years, the internet has become the primary information source for trip planning purposes Xiang et al. (2015)). Today, especially social media and the adoption of mobile devices exert an increasing impact on the customer's travel planning and booking behavior. Recent studies empirically confirm the growing importance of online distribution channels and 
an increasing importance of intermediary services.

A HOTREC survey among more than 2,000 European hoteliers finds that direct bookings account for $55 \%$ of all bookings and have dropped by 4 percentage points (pp) since 2013, while the direct online channel has remained approximately constant at close to 7\%. Bookings via OTAs have increased by 3 pp to $22 \%$ in the same time frame ${ }^{6}$ The survey also shows an increasing concentration in online hotel booking. Among bookings via OTAs, the three major OTAs Booking.com, Expedia and HRS account together for more than $90 \%$ of all bookings. The increased availability of distinct sales channels opens the possibility to adopt a multi-channel distribution strategy for the hotels. Stangl et al. (2016) find in a country study for Germany, Austria and Switzerland that hotels on average use eight distinct offline and online channel categories and have prices published at 3.6 OTAs. As we explain in more detail in subsection 6, this finding is consistent with the data collected from Kayak in which we observe that hotels are usually present at more than one online channel (i.e. they multi-home). According to our data (see Subsection 4.2), hotels publish room offers on average at 4.4 online sales channels (OTAs and the direct online channel).

\subsection{Best price clauses and competition policy}

The NCAs in Europe generally agreed that wide best price clauses restrict competition between OTAs for commission rates that hotels have to pay for every booking at an OTA 4 Under a wide BPC, an OTA obliges the hotel not to charge a higher price on the OTA than on almost any other booking channel, which in particular includes other OTAs and the hotel's own direct sales channels. ${ }^{8}$ For a hotel which complies with the wide BPCs and which is present at more than one OTA, as is typically the case, an OTA lowering its commission rate cannot expect to become the price leader because the hotel is not allowed to pass on this cost reduction into lower prices at just this OTA.

\footnotetext{
${ }^{6}$ HOTREC (2016) Survey on Hotel Online Distribution (http://www.tophotel.de/20-news/7186hotrec-studie-die-macht-der-online-buchungsportale-nimmt-zu.html, last accessed 30 July, 2016).

${ }^{7}$ Bundeskartellamt (2015) par. 167, Konkurrensverket (2015) par. 21-22, Autorité de la concurrence par. 115-122, Autorità Garante della Concorrenza e del Mercato (2015) par. 6-8. See Annex IV for more detailed references of the decisions.

${ }^{8}$ Non-public loyalty schemes, contracts with enterprises and (physical) travel agencies were usually excluded from this BPC. In addition to the price parity on (almost) all sales channels, the wide BPCs required that the offer regarding all other conditions is at least as good as the offer on other sales channels, and that the hotel offers at least the same room availability to the OTA as in other channels.
} 
Different from the common view that wide BPCs restrict competition for commission rates, the European NCAs disagreed on whether narrow BPCs likewise effectively restrict competition among OTAs. Narrow BPCs prohibit the hotel from publishing lower prices on its direct online sales channels than at the OTA that imposes the clause. However, a narrow BPC does not contractually restrict the hotel's room prices at other OTAs. In line with the different assessments, the NCAs reached quite different decisions.9

Germany's Bundeskartellamt prohibited all BPCs of the OTA HRS - the former number one in Germany - already in December 2013. In April 2015, the NCAs in France, Italy and Sweden instead accepted Booking.com's commitment to use at most narrow BPCs in Europe from July 2015 onward. Expedia followed by announcing in July 2015 to use a similar narrow BPC in Europe.

However, the narrow BPCs have been challenged in various countries shortly after their establishment. The French parliament overturned the NCA's acceptance of narrow BPCs already in July 2015 with a law that generally prohibits BPCs of OTAs. In December 2015, the German NCA prohibited the by then narrower clauses of Booking.com and is continuing the investigation against Expedia. Outside of Europe, instead, we understand that major OTAs still use wide BPCs in various countries.

\section{Data}

\subsection{Data source Kayak}

We use Kayak data on prices of hotel rooms on different online sales channels. ${ }^{10}$ Kayak is a meta travel search engine that collects information from various online channels such as the OTAs Booking.com, Expedia and the direct online channel. We understand that Kayak derives revenues from advertising placements on its websites and mobile apps and from sending referrals to travel service providers and OTAs.11

\footnotetext{
${ }^{9}$ See Annex IV for a list of the different decisions.

${ }^{10}$ We use the German edition of the internet site www.kayak.de. Since 2013, Kayak is a subsidiary of the Priceline Group, which previously also acquired the online travel agencies Booking.com (2004) and Agoda.com (2007).

${ }^{11}$ Priceline Group Inc. Annual Report 2015 (p.2). See http://ir.pricelinegroup.com/annuals.cfm; last accessed 25 September, 2016.
} 
There are two different kinds of information about hotels that appear on Kayak. ${ }^{12}$ First, general information such as a description of the hotel, the location and contact details. Second, information on availabilities and prices can be submitted to Kayak in real time. In order to provide this information on Kayak, a hotel can either be listed with an OTA or it can make use of its own booking engine or a third-party booking engine provider.13

A typical Kayak request consists of a travel destination, the travel dates, the number of travelers and the number of rooms, e.g. two persons looking for one room in Rome for an overnight stay in two weeks from today. Kayak uses the information provided from OTAs and the hotels' direct sales channels to display a list of available hotels. For every hotel, Kayak lists the prices of the available sales channels. 14 We refer to the list of all available sales channels for a particular hotel at a particular travel date as a 'Kayak request'.

We collect Kayak prices for all listed hotels from a wide range of cities:

- the 25 biggest German cities,

- a selection of 20 pairs of German and non-German cities near the German border, and

- a list of the fifteen biggest cities and fifteen popular tourist destinations for the five countries Austria, Italy, Sweden, France and Canada.

Data is being collected from January 26, 2016 onward. The corresponding list of locations and starting dates for data collection can be found in Annex I. Data collection takes place on a daily basis from various servers inside Germany. Prices are collected for overnight stays for two persons in one room on the same day and the 7th, 14th, 21th and 28th day ahead 15

In the Kayak data we observe 73 distinct sales channels which can be classified as OTAs and direct channels. Some OTAs belong to the same company group (see Annex V for

\footnotetext{
${ }^{12}$ See https://www.kayak.com/hotelowner, last accessed 10 August, 2016.

${ }^{13}$ Booking engines are provider that offer the services necessary to connect the hotel to Kayak such as Fastbooking, Travelclick or Derbysoft.

${ }^{14}$ Also, Kayak sometimes includes itself in the list of hotel price offers. However, a click on the "Kayak offer" redirects to OTAs which also belong to the Priceline Group such as Booking.com. Therefore, whenever we observe a Kayak entry, we substitute it with the corresponding underlying Priceline OTA and eliminate potential duplicates.

${ }^{15} \mathrm{On}$ certain dates, we were able to collect prices for more travel dates than $0,7,14,21$ and 28 days in advance of the booking date, e.g for all days within a 30 day period between booking and travel date, but due to technical difficulties on some days we collected less data. In the analysis, only the observation with travel dates $0,7,14,21$ and 28 days ahead are included.
} 
details). Among the direct channel listings, two categories can be distinguished. On the one hand, there are hotels that make use of a third party service provider that supplies the software necessary in order to connect to Kayak. On the other hand, there are hotels that make use of their own technological interface to transmit information to Kayak. Kayak displays the direct channel price of a hotel and provides a link to the hotel's own website. We take this into account for our analyses where necessary.

\subsection{Summary statistics of the Kayak data set}

The period of observation ranges from January 2016 until July 2016. Each observation in the data set refers to a hotel room at a specific travel date which is on offer at a certain search date. For each search request we observe all available sales channels listed on Kayak. In total, the data set consists of more than 15 million observations. On average, a hotel has prices posted on 4.35 online sales channels (OTAs and direct channel). In 68\% of all observations we find that hotels have published prices on at least two channels.

The average price is at $118 \mathrm{EUR}$, ranging from 5 EUR to 19,997 EUR ${ }^{16}$ Conditional that the hotel has prices published on at least two platforms, the average standard deviation of prices is 14 EUR. The corresponding average coefficient of variation between all available price offers in one Kayak request is 0.09 . In $49 \%$ of all observations with at least two channels, there is a strict minimum price. For the observations with strict minimum price, the average difference between the lowest and second lowest price is at $14 \%$ of the lowest price.

The average hotel category in the data set is 2.4 stars out of five, the average Kayak rating is at 8 out of 10 points. However, the latter variable is only available in $82 \%$ of all observations. Kayak states both the number of hotels in a city listed with offers at a certain travel date and the total number of hotels in the city. We use the fraction of hotels that are not listed with offers at a certain travel date over all hotels as a measure of local hotel occupancy. It has an average value of $61 \%$.

Two dates have to be distinguished: The date when we searched for a hotel and the planned travel date. When we refer to dates in the subsequent analysis we mean the search dates, if not stated otherwise.

\footnotetext{
${ }^{16}$ Prices above 20,000 EUR were excluded.
} 
Table 1: Summary statistics

\begin{tabular}{lccccc}
\hline \hline \multicolumn{1}{c}{ Variable } & Mean & Std. Dev. & Min. & Max. & N \\
\hline Number of listings & 4.35 & 3.63 & 1 & 24 & 15187685 \\
At least two listings & 0.68 & 0.47 & 0 & 1 & 15187685 \\
Mean price in Euro & 117.74 & 128.22 & 5 & 19996.5 & 15187685 \\
Std.Dev. price & 13.98 & 72.71 & 0 & 13611.1 & 10471241 \\
Coefficient of Variation & 0.09 & 0.15 & 0 & 3.61 & 10471241 \\
Strict minimum price exists & 0.49 & 0.5 & 0 & 1 & 10367780 \\
Rel. diff. (str.) first two lowest prices & 0.14 & 1.34 & 0 & 349.84 & 5132018 \\
Hotel category in stars & 2.4 & 1.43 & 0 & 5 & 15187685 \\
Kayak hotel rating & 8.07 & 0.9 & 1.7 & 10 & 12456889 \\
Percentage of non-listed hotels & 0.61 & 0.16 & 0 & 1 & 15173151 \\
\hline
\end{tabular}

\subsection{Validation of price accuracy on Kayak}

In order to validate the accuracy of the Kayak data, we manually conducted a comparison of prices and qualitative features between hotel offers on www. kayak. de with corresponding offers on the websites of the major OTAs Booking.com, Expedia and HRS and the hotels. The comparison sample includes 171 booking requests for travel dates ranging from June to August 2016. As we observe more than one channel per request on Kayak, we validated the price accuracy between Kayak and the channel price in 255 cases. Similarly, we investigate for every channel whether it is the price leader in the corresponding Kayak request and whether this information on the price structure is maintained on the sales channels. With this validation we check in 181 cases the correctness of the price structure across channels. For a detailed description of the validation analysis see Annex II.

Our manual check revealed that in general the qualitative features of a hotel room offer, such as the cancellation policy and whether breakfast is included, are identical on Kayak and on the actual sales channels, whenever rooms are available on both sources. ${ }^{17}$ However, we did observe deviations between Kayak prices and the prices on OTAs and the hotel websites in various instances. In particular, prices on Kayak tend to be higher than on the sales channels in one quarter of all observations. Nevertheless, in two-thirds of all the 255 cases in which Kayak price and channel price are comparable, prices on both sources virtually coincide within a tolerance range of \pm 3 EUR. With a tolerance of \pm 5 EUR the prices are consistent in approximately 3 out of 4 cases. With regard to the order

\footnotetext{
${ }^{17}$ In three cases (Booking.com twice, HRS once) Kayak displayed available rooms while there was no offer on the corresponding sales channel.
} 
of prices across channels, we find that the price leader is correctly detected by Kayak in more than $90 \%$ of all cases. Furthermore, we cannot identify systematic differences in the errors that would indicate a favorable treatment of a particular channel. These findings reassure us that the Kayak is an adequate source for our evaluation of the price structure across sales channels in relation to differences of the BPCs.

\section{Conjectures, identification and methodology}

As discussed in the introduction, the focus of the present article is to analyze on which channels hotel room offers are published and the price setting behavior of hotels across channels in relation to BPCs. Recall that a BPC restricts price differentiation to the extent that hotels may not charge prices on channels covered by the BPC below the price charged at the OTA imposing the clause. Moreover, there are related clauses, such as availability parity for wide, and a minimum availability requirement for narrow BPCs. These further restrict a hotel's sales strategy. A hotel might only be able to avoid an availability clause by not doing business with an OTA at all. The decision of where to publish prices might thus depend on which parity clauses are in place. Subsequently, we formulate conjectures in relation to both publishing and pricing decision.

\subsection{Conjectures in relation to the decision on which channels a hotel publishes prices}

An OTA's price parity clause constrains the price setting behavior of a hotel. Such a BPC can make it unprofitable for some hotels to sign a contract with this particular OTA. A reduction of price parity clauses could, therefore, induce more hotels to start publishing room prices on that OTA or on other channels for which the hotel was too constrained before.

The removal or reduction of an availability parity clause might have opposing effects on the hotels' publishing decisions at the intensive and the extensive margin. Under Booking.com's wide parity clauses, for example, the availability parity requires a hotel always 
to offer at least the same availabilities at Booking.com as on any other OTA. Under their new narrow parity clauses, neither Booking nor Expedia apply room availability parity, either in relation to other OTAs, or in relation to the hotel's own website. However, Booking.com does require the hotel to make available on Booking.com's website a minimum allocation of rooms 18

An availability requirement might thus induce hotels to generally publish prices on fewer channels (extensive margin) - in particular some hotels might prefer to not become active at an OTA that requires availability. In summary, the reduction of both price and availability parity clauses should increase the incentives for hotels to make prices available at more OTAs. We particularly expect more publications at the OTA that reduces its BPC and therefore test

Conjecture 1. A decrease in the scope of a the parity clauses (in particular price and availability) results in more price publications at the extensive margin, and in particular at the OTA which has reduced the BPC.

At the same time, we expect that an availability parity increases the number of channels with price publicatins at the intensive margin when hotels are obliged to post all their room offers also at the OTA. Following the reduction of a parity clause, hotels might use the new freedom to occasionally reduce offers at an OTA if they are able to sell their rooms on more profitable channels. To the contrary, an abolished price parity could increase the profitability of a more diversified channel use and therefore induce hotels registered at an OTA to be listed more often.

As we investigate listing decisions at the extensive and at the intensive margin, we are able to distinguish between effects of the availability parity and the price parity on the intensive publishing decisions. Especially, the net effect on the intensive channel use gives an indication which parity predominantly constrains hotels in their publishing decisions. If it is positive, intensive channel use increases in reaction to a decrease in the scope of a BPC. This would indicate that the effect of the price parity clause dominates. If the net effect is negative at the OTA that imposed the constraint, this would indicate that the availability parity has been the more important constraint.

\footnotetext{
${ }^{18}$ For Booking.com refer to https://news.booking.com/bookingcom-announces-support-of-newcommitments-in-europe and for Expedia to http://www.hotelnewsnow.com/Articles/26715/Expediaamends-rate-parity-clauses; last accessed 28 September, 2016.
} 
However, as noted in the introduction, the availability parity can be interpreted as an ancillary clause to prevent circumvention of the price parity clause. In addition with the fact that under the narrow parity clauses the availability parity is considerably weaker than under the wide, we expect that in the case of Booking.com's narrow BPC in Germany the price parity clause imposes a larger constraint on price publications at the intensive margin than the availability parity. As a consequence of the expected prevalence of the price parity, we additionally expect that a reduction of a BPC mainly affects the channels that get increased price setting freedom from this reduction. In particular, if a channel was covered by the BPC and regains price setting freedom from the BPC reduction, the hotel should find it profitable to make use of this channel more frequently. Therefore:

Conjecture 2. A decrease in the scope of a BPC results in a higher frequency of price publications at the intensive margin and mainly affects the channels that are no longer covered by the $B P C$.

\subsection{Conjectures in relation to pricing across channels}

In addition to the publications of room offers across channels, the second major question is how BPCs relate to the price structure for a hotel room across several distribution channels. There are various reasons why a hotel might want to charge different prices on different distribution channels. These include different

- distribution costs across channels;

- elasticities of demand on each channel because different customers or competitors are active on the channel;

- costs to adjust prices on each channel.

Online prices of goods and services - including hotel rooms - generally exhibit considerable price dispersion across different distribution channels (Ghose and Yao (2011), Sun et al. (2015)). For a hotel the direct channel is likely to typically have lower marginal distribution costs per booking than an OTA booking because no OTA commission needs to be paid. The recent endeavors of hotel associations to take measures against the BPC 
such as the "Book Direct" campaign of HOTREC 19 confirm that hotels typically have an interest to capture as many bookings as possible via the direct channel. Hotels might, therefore, have an incentive to set lower prices on the direct channel than on OTAs where they have to pay commission fee for every mediated booking and the same transaction is, therefore, less profitable. Hence, we test

Conjecture 3. The direct channel price is typically not above the price at an OTA using a BPC.

A BPC obliges hotels not to charge lower prices on channels that are covered by the BPC than the price charged at the OTA imposing the clause. Therefore, we test

Conjecture 4. The channel prices that are covered by a BPC are not below the price at the OTA that imposes the BPC.

We also analyze (strict) price leadership in the sense that there is one channel offering the (strictly) lowest price among all channels in one Kayak request. Which channel is the price leader for a given hotel is important for hotel online distribution. At least a fraction of the customers should prefer to book at the lowest price possible.

BPCs require prices of other channels to be larger or equal compared to the price of the OTA that imposes the BPC. Accordingly, there should be less often a strict price leader across channels when several BPCs are in effect. Therefore, we test

Conjecture 5. The wider the scope of the BPCs of the major OTAs, the less frequently there is a strict price leader across channels.

Conjectures 3 , 4 and 5 can be related to static differences across BPC regimes. As we have also captured the removal of Booking.com's narrow BPC in Germany, we can also take changes in the price structure associated with a decrease in the scope of a BPC into account. The narrow BPC obliged hotels to not set a lower price at the direct channel than at Booking.com. We therefore test

Conjecture 6. Hotels price their direct online channel below the OTA more often once the OTA removes its narrow $B P C$.

\footnotetext{
${ }^{19}$ See http://www.hotrec.eu/bookdirect.aspx; last accessed 31 August, 2016.
} 
In Germany, the only major OTA that still imposes a narrow BPC is Expedia. As Booking.com removed its narrow BPC, hotels may now consider it profitable to decrease prices at Expedia and the direct channel without having to maintain price parity between the direct channel and Booking.com. Given this asymmetry, we test

Conjecture 7. In Germany, hotels set prices at Expedia more often below the prices at Booking.com after Booking.com abolished its narrow BPC.

This conjecture hinges on the question whether it is attractive for hotels to set lower prices at Expedia. This could be the case if the value-for-money is higher at Expedia than at Booking.com. As we have not found evidence for reduced commission rates following the changes in the $\mathrm{BPC}$, it is possible that the price relation between Expedia and Booking.com does not change due to more intense competition. Therefore, this conjecture might also be interpreted as an additional test for increased OTA competition between Booking.com and Expedia.

One might wonder whether, following the prohibition of Booking.com's BPC, the narrow BPC of Expedia prevents hotels from setting the direct online channel prices below all OTA prices to become the price leader. We conjecture that there is still scope for such a strategy, either because a hotel is not active at Expedia, or because a hotel violates Expedia's BPC. The ongoing investigation of the German competition authority against the narrow BPCs of Expedia might encourage hotels to assume that the clause will not be enforced by Expedia anymore. We therefore test

Conjecture 8. The hotel's direct online channel becomes the strict price leader more frequently once an OTA removes its narrow BPC.

\subsection{Methodology}

Our empirical approach is twofold: First, we point out a set of interesting observations in relation to channel choice and pricing decisions across countries and channels by means of cross section statistics. We analyze data of the following countries ${ }^{20}$

1. Countries without BPCs: Currently France and Germany (in Germany at least HRS and since February 2016 also Booking.com; Expedia still has a narrow BPC).

\footnotetext{
${ }^{20}$ See Annex I for a detailed overview of countries and cities covered.
} 
2. Narrow BPC countries: All EU member states except for Germany and France as regards the major OTAs Booking.com and Expedia. Our data captures mainly Italy, Sweden and Austria, as well as various cities close to the German border.

3. Wide BPC countries: Today only non-EU countries as regards at least the major OTAs Booking.com and Expedia. We have collected data for Canada.

Second, we analyze the developments in Germany and how these differ from the other countries. For this, we use regression analyses to control for possibly confounding factors. Hotel fixed effects are used in all regressions in order to control for unobserved heterogeneity across hotels and thereby composition effects over time. Factors like the hotel size, the type of the hotel (hotel chain, independent hotel, hotel garni, etc.) or the management's price and distribution strategy are in general likely to influence the decision of a hotel where to publish prices and how to set prices across channels. We assume these factors to stay constant during the period of observation and thus to be covered by the fixed effects. Note that also other time constant observed variables such as hotel stars or country are not included in the analysis.

In the estimations we exploit the within hotel variation. If not stated differently, we include as control variables the time interval between booking date and travel date, the weekday of the first travel day and the share of non-available hotels. The latter serves as an approximation for the occupancy in the city where the hotel is located. All regressions are computed such that Germany is the reference country.

Due to high computational effort in case of fixed effects, we conduct the regressions on dichotomous indicator variables with the linear probability model (LPM) rather than with an index model such as probit and logit. Although such a non-linear model is theoretically a more rigorous approach, we follow Wooldridge (2010) that the LPM often yields good estimates of the partial effects on the response probability. Standard errors are computed to be robust to heteroscedasticity. 


\subsection{Identification}

Conjectures 3 and 4 relate to differences across BPC regimes. We investigate these partly with cross section statistics which capture differences in the BPCs across countries. The identifying assumption here is that differences across countries are due to the different $\mathrm{BPC}$ regimes. We cannot exclude, however, that there are also other country-specific differences which affect our measures, such as the variation of prices across channels. Nevertheless, we consider this a useful first step given the limited empirical evidence that is available so far.

Importantly, we observe variation in the $\mathrm{BPC}$ regime over time in Germany. The latest prohibition decision in Germany was taken in December 2015 against Booking.com, with the obligation for Booking.com to remove the narrow BPC by February 2016 ${ }^{21}$ We use this variation to test conjectures 1, 2, 6, 7, 8, which relate to adjustment processes after the reduction of the scope of a BPC. For this, we compare the changes in the market outcome in Germany with the changes in other countries without such a change of the BPCs in the relevant time frame. Our identifying assumption in this case is that there are no other country-specific developments since January 2016 - except for the ones which we can control for, such as the utilization rates of hotels at the city level.

\section{Analysis of hotel room availability across channels}

\subsection{Cross sectional observations}

Finding 1: Hotel prices are most often published at the OTAs Booking.com, Expedia and HRS

In our data set, Booking.com is the channel that exhibits the highest penetration as $94 \%$ of all hotels publish prices there at least once, followed by Expedia with about $50 \%$ (Table

2. first data column). Across the covered countries, $16 \%$ of all hotels make use of the OTA HRS. In contrast, for Germany, 50\% of all observed hotels had offers listed at least once

\footnotetext{
${ }^{21}$ See Annex IV for an overview of the decisions.
} 
at HRS (country statistics not reported individually). This can be attributed to the fact that HRS is a German incumbent.

Table 2: Channel use

\begin{tabular}{lcc}
\hline Channel (major channels only) & $\begin{array}{c}\text { Fraction of hotels that } \\
\text { used channel at least } \\
\text { once }\end{array}$ & $\begin{array}{c}\text { Frequency of channel } \\
\text { use (given hotel used it } \\
\text { at least once) }\end{array}$ \\
\hline Direct channel (total) & $10 \%$ & $82 \%$ \\
Direct channel (service provider) & $4 \%$ & $62 \%$ \\
Direct channel (own interface) & $7 \%$ & $94 \%$ \\
Booking.com & $94 \%$ & $88 \%$ \\
Expedia & $46 \%$ & $90 \%$ \\
HRS & $16 \%$ & $88 \%$ \\
\hline Base & All 46,223 hotels & All Kayak requests of \\
& observed during the & hotels where the \\
& observation period & channel has been used \\
& & at least once
\end{tabular}

\section{Finding 2: Direct online channel prices are available in about $14 \%$ of all Kayak requests}

We observe prices on the direct online channel on Kayak at least once for approximately $10 \%$ of all hotels. Out of these hotels, about two thirds can be identified as hotels that have their own booking engine connected to Kayak, whereas the other third uses service providers such as FastBooking. Among the 15 million Kayak requests, a direct channel offer is contained in $14 \%$ of all requests on Kayak.

The hotels do not always list offers at an OTA or their direct channel (Table 2, third column). A usage frequency of a channel below 100\% could arise either if a large fraction of hotels starts or ceases to use this channel during the observation period. Another possibility is that hotels have the ability to react more flexibly to changing market conditions on this channel. On average, a hotel that is at least once listed with an OTA offers rooms on it in almost $90 \%$ of all Kayak requests. Hotels with an own booking engine exhibit a similar frequency as OTAs, while the direct channel via a service provider is only used in $60 \%$ of all requests. This may be an indication that adoption or termination is a prevalent phenomenon for this channel or that hotels using a service provider react more flexibly to changing market conditions with respect to direct channel offers. A higher usage frequency at OTAs may be, for example, caused by OTAs' availability parities. 
Finding 3: The availability frequencies vary by country - but are comparable for Booking.com and Expedia in Europe

Table 3: Summary statistics by countries

\begin{tabular}{lccccc}
\hline & $\begin{array}{c}\text { Number of } \\
\text { listings }\end{array}$ & $\begin{array}{c}\text { Frequency } \\
\text { Book- } \\
\text { ing.com }\end{array}$ & $\begin{array}{c}\text { Frequency } \\
\text { Expedia }\end{array}$ & $\begin{array}{c}\text { Frequency } \\
\text { HRS }\end{array}$ & $\begin{array}{c}\text { Frequency } \\
\text { direct channel }\end{array}$ \\
\hline \hline Germany & 5.2 & $80 \%$ & $60 \%$ & $64 \%$ & $16 \%$ \\
France & 5.1 & $88 \%$ & $74 \%$ & $13 \%$ & $22 \%$ \\
Italy & 3.4 & $83 \%$ & $52 \%$ & $6 \%$ & $4 \%$ \\
Sweden & 4.5 & $94 \%$ & $71 \%$ & $12 \%$ & $20 \%$ \\
Austria & 3.5 & $92 \%$ & $45 \%$ & $27 \%$ & $11 \%$ \\
Canada & 5.4 & $90 \%$ & $83 \%$ & $3 \%$ & $38 \%$ \\
\hline
\end{tabular}

The number of channels with price publications at Kayak for an average hotel room request differ by country and range from 3.5 listings in Italy and Austria, 4.5 listings in Sweden up to 5.4 listings in Canada (Table 3, data column 1).

In all countries Booking.com is the mostly used channel with a frequency ranging from $80 \%$ in Germany to $94 \%$ in Sweden. Number two is Expedia with frequencies from $45 \%$ in Austria to $83 \%$ in Canada.

Compared to the channels Booking.com and Expedia that are very prevalent in all countries of the data set, the presence of the German OTA HRS varies more across countries. HRS is especially present in Germany (60\%) and Austria (45\%), while it appears only in $3 \%$ of all Canadian Kayak requests.

The direct channel also exhibits a high variation across countries, with only $4 \%$ in Italy and an extraordinary $38 \%$ in Canada. One has to take into account that a meta search site such as Kayak does not obtain direct online channel information automatically. The variation across countries may, therefore, be due to different degrees in the use of interface software or service providers which transfer this information to sites such as Kayak.

\subsection{Effects of Booking.com's removal of the narrow best price clause in Germany on the availability of price offers}

For all countries the frequency of price publications at Booking.com increase over time (Figure 1). This indicates Booking.com's growing importance in online hotel distribution. 
The frequency in Germany starts from an average level of around $73 \%$ and exhibits the sharpest increase in the observation period.

Figure 1: Booking.com listing frequency at Kayak by country

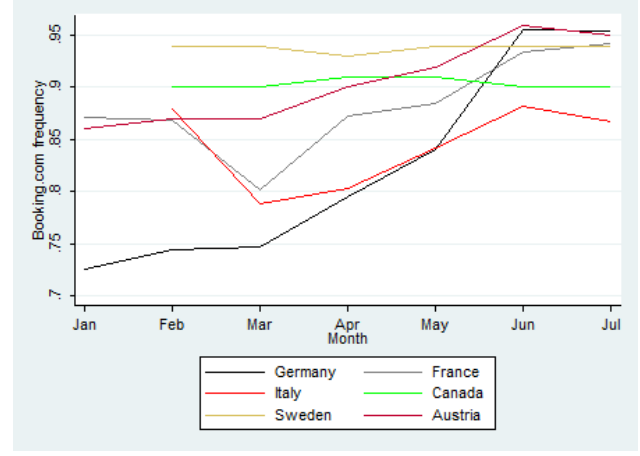

We analyze below whether this can be attributed to the abolition of Booking.com's BPCs in Germany, as the implied less restrictive contract terms might make it more attractive for hotels to list with Booking.com. The following regressions address the intensive and extensive publications decisions (Conjectures 1 and 2).

Finding 4: On the extensive margin, there is a distinctive increase in the frequency of publications at Booking.com in Germany, and also increases at Expedia, the direct channel and HRS

According to Conjecture 1, a reduction in the scope of a BPC yields an increase in price publications at the extensive margin, especially for the OTA that narrows down its BPC. This can be tested for Germany where Booking.com had to waive its narrow BPC from February 2016 onwards.

We test this conjecture with a data set where each observation is a hotel in a specific month. The dependent variable equals 100 if a particular channel (such as Booking.com) was used by the hotel at least once in that particular month according to the Kayak data, and 0 otherwise. The linear country-specific trend captures whether hotels use the channel in later months but not early in 2016 (extensive use). The variable "Share of non-listed hotels" is the monthly average for the respective location 22 The regression results are reported in Table 4 .

\footnotetext{
${ }^{22}$ The control variables for the time interval between booking and travel date and the weekday of the first travel day are not included.
} 
The second data column of Table 4 shows a positive trend in the share of hotels using Booking.com at least once in each month. Each month, the share of hotels using Booking.com increases by three percentage points (pp) in Germany. The coefficients on the interactions of the time trend with the other countries (i.e. the deviations from the German trend) are significantly negative. These time trends are thus less pronounced for the other countries where no change in the BPC regime took place in the investigated time frame. The negative deviations (in absolute values) from the German trend range from $0.8 \mathrm{pp}$ in Italy to approximately $3 \mathrm{pp}$ in Canada and Sweden, where the trend of Booking.com's price publications frequencies is close to zero.

Table 4: Extensive channel use (at least once in a month)

\begin{tabular}{lcccc}
\hline \hline & $(1)$ & $(2)$ & $(3)$ & $(4)$ \\
& Direct & Booking.com & Expedia & HRS \\
\hline Trend (Base: Germany) & $0.19^{* * *}$ & $3.34^{* * *}$ & $0.27^{* * *}$ & $0.09^{* * *}$ \\
$\Delta$ Trend France & $0.39^{* * *}$ & $-1.52^{* * *}$ & $0.54^{* * *}$ & 0.05 \\
$\Delta$ Trend Italy & $-0.10^{* *}$ & $-0.83^{* * *}$ & $-0.16^{* * *}$ & $-0.11^{* * *}$ \\
$\Delta$ Trend Sweden & $-0.33^{* * *}$ & $-3.09^{* * *}$ & -0.17 & -0.02 \\
$\Delta$ Trend Austria & $0.43^{* * *}$ & $-1.83^{* * *}$ & -0.09 & 0.09 \\
$\Delta$ Trend Canada & $-0.18^{* *}$ & $-2.93^{* * *}$ & $-0.20^{* *}$ & $-0.10^{* *}$ \\
$\Delta$ Trend Other countries & $-0.26^{* * *}$ & $-3.07^{* * *}$ & 0.02 & $-0.08^{*}$ \\
Share of non-listed hotels & -0.11 & $-21.07^{* * *}$ & $2.88^{* * *}$ & -0.14 \\
Hotel FE & Yes & Yes & Yes & Yes \\
\hline Observations & 220,233 & 220,233 & 220,233 & 220,233 \\
$R^{2}$ & 0.005 & 0.066 & 0.005 & 0.001 \\
Adjusted $R^{2}$ & 0.005 & 0.066 & 0.005 & 0.001 \\
Within $R^{2}$ & 0.00 & 0.07 & 0.01 & 0.00 \\
\hline \hline
\end{tabular}

Heteroscedasticity-robust standard errors not reported.

${ }^{*} p<0.1,{ }^{* *} p<0.05,{ }^{* * *} p<0.01$

Moreover, the increase for Booking.com in Germany is stronger than for the other channels (compare the increase in Booking.com price availabilities with the other channels in data columns 1, 3 and 4 of Table 4). The significant and positive coefficient on the extensive direct channel use of $0.19 \mathrm{pp}$ in data column 1 might allude to the fact that Booking.com's narrow BPC indeed put a considerable constraint on the direct channel. After its abolition, it might be reasonable for more hotels to engage into direct online sales. Interestingly, in France, where narrow BPCs were already abolished in July 2015, and in Austria, where an abolition of the narrow BPCs is expected 23 the increase of the

\footnotetext{
${ }^{23}$ See http://hotelanalyst.co.uk/2016/08/01/austria-moves-on-rate-parity/; last accessed 30 August, 2016 .
} 
direct channel use at the extensive margin is even stronger than in Germany during the observation period (by $\Delta 0.39$ and $\Delta 0.43$ pp per month). Due to the (expected) abolition of BPCs from all OTAs, it seems that the increased direct channel adoption in these countries is even stronger than the increasing adoption in Germany in reaction to the abolition of Booking.com's BPC.

The regressions on the extensive channel use of Booking.com confirm Conjecture 1: there is a significant positive trend in the extensive channel use of Booking.com following the removal of its narrow $\mathrm{BPC}$ in Germany that is significantly stronger than in the other countries. The other sales channels in Germany seem to be also positively affected by the abolition of Booking.com's narrow BPC (although the picture across countries is less clear). That the increase in the extensive channel use is strongest for Booking.com is in line with the argument underlying Conjecture 1 that hotels are now particularly willing to register with this OTA as they are not constrained by its BPC anymore.

\section{Finding 5: On the intensive margin, there is a distinctive increase in the price availabilities at Booking.com, Expedia and the direct channel in Germany}

In the following we analyze the intensive channel use. According to Conjecture 2, price parity and availability parity exert opposing effects on price availabilities at the intensive margin. However, we expect that the price parity imposes a larger constraint on the price publications decisions than the availability parity. As a consequence, the net impact of a reduction in the scope of a $\mathrm{BPC}$ on the intensive channel use should be positive.

Additionally, the channels exempted from the BPC should be those that are mainly affected from the policy change because these channels were mainly constrained by the $\mathrm{BPC}$ at the intensive margin. In Germany, Booking.com had to abolish its narrow BPC that explicitly only restricted the price setting on the direct online channel.

We test this conjecture with regressions where the dependent variable equals 100 if the channel is present at the Kayak request, and 0 otherwise. We only include hotels which used the respective channel already in January or February and measure whether the channel is used more intensively in later months than early in 2016 . Note that by this rule, out of all observations, between $6 \%$ for Expedia and the direct channel to $14 \%$ for 
Booking.com are omitted in the regressions 24

The frequency of price publications at the intensive margin significantly increases over time for the direct channel, Booking.com and Expedia in Germany (by 0.85, 0.43 and 0.19 pp each month according to the first data row in Table 5). By contrast, HRS does not experience a time trend significantly different from zero in the intensive channel use in Germany. The increase in intensive channel use is the largest in magnitude for the direct channel. This confirms conjecture 2 as apparently the direct channel that was the most constrained channel by Booking.com's price parity. The increased use of Expedia might indicate that hotels expect an abolition of Expedia's narrow BPCs too, as the Bundeskartellamt's investigation against Expedia is still proceeding (Hunold $(2016))$. The prohibition of HRS's BPC has already taken place in December 2013, so that there is arguably no significant adjustment process taking place anymore in 2016.

Table 5: Intensive channel use (if observed in February)

\begin{tabular}{lcccc}
\hline \hline & $(1)$ & $(2)$ & $(3)$ & $(4)$ \\
& Direct & Booking.com & Expedia & HRS \\
\hline Trend (Base: Germany) & $0.85^{* * *}$ & $0.43^{* * *}$ & $0.19^{* * *}$ & 0.01 \\
$\Delta$ Trend France & $-2.84^{* * *}$ & $-0.43^{* * *}$ & $-0.40^{* * *}$ & $-1.07^{* * *}$ \\
$\Delta$ Trend Italy & $-3.42^{* * *}$ & $-0.74^{* * *}$ & $-0.25^{* * *}$ & $-1.38^{* * *}$ \\
$\Delta$ Trend Sweden & $-1.60^{* * *}$ & $-0.55^{* * *}$ & $-0.46^{* * *}$ & $-1.40^{* * *}$ \\
$\Delta$ Trend Austria & 1.02 & -0.25 & $-1.45^{* * *}$ & $-2.11^{* * *}$ \\
$\Delta$ Trend Canada & $-1.55^{* * *}$ & $-0.81^{* * *}$ & $-0.51^{* * *}$ & $-2.26^{* * *}$ \\
$\Delta$ Trend Other countries & $-2.98^{* * *}$ & $-0.46^{* * *}$ & $-0.88^{* * *}$ & $-1.49^{* * *}$ \\
Share of non-listed hotels & $-28.66^{* * *}$ & $-22.29^{* * *}$ & $-31.00^{* * *}$ & $-46.70^{* * *}$ \\
7 days before & 0.09 & $0.18^{* * *}$ & $0.67^{* * *}$ & $1.14^{* * *}$ \\
14 days before & $0.63^{* * *}$ & $0.28^{* * *}$ & $1.15^{* * *}$ & $1.91^{* * *}$ \\
21 days before & $0.74^{* * *}$ & $0.44^{* * *}$ & $1.10^{* * *}$ & $2.80^{* * *}$ \\
28 days before & $0.90^{* * *}$ & $0.26^{* * *}$ & $0.99^{* * *}$ & $3.02^{* * *}$ \\
Hotel FE & Yes & Yes & Yes & Yes \\
Weekdays & Yes & Yes & Yes & Yes \\
\hline Observations & $2,022,658$ & $11,116,947$ & $8,615,682$ & $2,986,772$ \\
$R^{2}$ & 0.019 & 0.009 & 0.011 & 0.029 \\
Adjusted $R^{2}$ & 0.019 & 0.009 & 0.011 & 0.029 \\
Within $R^{2}$ & 0.02 & 0.01 & 0.01 & 0.03 \\
\hline \hline
\end{tabular}

Heteroscedasticity-robust standard errors not reported.

${ }^{*} p<0.1,{ }^{* *} p<0.05,{ }^{* * *} p<0.01$

The coefficients for the deviations in the other countries are mostly significantly negative. In several instances the country-specific deviation from the German trend is larger in

\footnotetext{
${ }^{24}$ Compare the number of observations in Table 5 with the total amount of Kayak requests in which these OTAs are listed (Table 20 in Annex V).
} 
absolute values than the coefficient on the German trend (row 1), which suggests an even negative trend. Note that we control for the local supply-demand balance by means of the share of non-listed hotels, which has a both statistically and economically highly significant negative coefficient.

The largest significantly negative deviations from the German trend can be observed for the direct channel (data column 1) and range from approximately minus 1.6 pp in Sweden and Canada to minus $3.42 \mathrm{pp}$ in Italy. This suggests that the intensive direct channel use is rather declining in these countries. The trend in Austria has a positive sign and is not significantly different from the German trend, indicating a similar development as in Germany.

For Booking.com (data column 2), the deviation of the French trend compared to the German trend of minus 0.43 pp suggests that the changes in intensive use of Booking.com are close to zero in France. The significant coefficients for the other countries - except for Austria - are even more negative, indicating that the intensive Booking.com use decreased in these countries as for the direct channel. Austria shows no significant deviation from the German trend for both these channels. This might indicate that Austria already undergoes a similar development as Germany after the Austrian NCA has announced to also prohibit the narrow BPCs in Austria in the course of 2016.

The regression results confirm Conjecture 2 by indicating that the abolition of Booking.com's narrow BPC is related to an increase in the intensive channel use, and in particular suggest that the constraint of BPCs on price publication decisions rather stems from price parity clauses than from availability clauses. The narrow BPC required the direct online channel price not to be lower than that at Booking.com. Now hotels publish their prices more often also at Booking.com, although the availability parity has been relaxed - possibly because setting lower prices at the direct channel than at Booking.com is not punished as much anymore, while before hotels might just not have published offers at Booking.com in such instances. The intensive channel use increases as well for Expedia in Germany, possibly because hotels might treat Expedia as Booking.com in view of a possible abolition of Expedia's BPC in Germany. The German trend is distinctive from the other jurisdictions where no policy change has taken place, except for Austria which might be attributed to the announcement of the Austrian NCA to also abolish narrow 
$\mathrm{BPC}$ in 2016.

Finding 6: The increase in the price availability in Germany is not a pure catch-up

The Booking.com price publication frequency in Germany starts from a considerably lower level than the frequencies in the other countries at the beginning of the observation period in 2016 (Figure 1). One might, therefore, wonder whether the increase in the publication frequencies of Booking.com in Germany can be fully attributed to the prohibition of its narrow BPC by the Bundeskartellamt.

An alternative hypothesis could be that Booking.com might undergo a general catchup process in regions where it is is less established. In order to distinguish between these two effects, we computed a control group of non-German cities which exhibit the same average publication frequency of Booking.com at the beginning of the observation period. However, for these cities Booking.com's publication frequency does not experience a comparable increase as in Germany. This is contrary to the conjecture that the increase of the Booking.com frequency is (only) due to a general catch-up process in regions that had a low Booking.com listing share at the beginning of the observation period. See Annex VI for a detailed description of the robustness check.

Additionally, we observe that the price availability frequencies of the other major OTAs in Germany stay approximately constant during the observation period: the price availability frequency of Expedia increased slightly from $64 \%$ in January to $69 \%$ in July, while the HRS frequency decreased very slightly from $68 \%$ to $66 \%$. This contradicts that there are major changes in the competitive situation during the observation period which could explain such a sharp increase of Booking.com's price availability frequency.

\section{Pricing across channels}

\subsection{Cross-sectional observations}

To address Conjectures 3 and 4 , we computed how often the direct channel price is strictly below, equal, or strictly above the price of the major OTAs. 
Table 6: Comparison direct channel and Booking.com

\begin{tabular}{lcccc}
\hline Country & $\mathrm{N}$ & $\mathrm{D}<\mathrm{B}$ & $\mathrm{D}=\mathrm{B}$ & $\mathrm{D}>\mathrm{B}$ \\
\hline Germany & 432,551 & $36 \%$ & $49 \%$ & $16 \%$ \\
France & 575,372 & $35 \%$ & $44 \%$ & $21 \%$ \\
Italy & 207,428 & $39 \%$ & $34 \%$ & $26 \%$ \\
Canada & 407,988 & $29 \%$ & $38 \%$ & $33 \%$ \\
Sweden & 76,533 & $43 \%$ & $31 \%$ & $26 \%$ \\
Austria & 68,753 & $44 \%$ & $34 \%$ & $22 \%$ \\
Others & 128,957 & $38 \%$ & $36 \%$ & $26 \%$ \\
\hline
\end{tabular}

Table 6 shows the price relation between Booking.com prices and direct channel prices for all Kayak requests that contain prices from both channels (the number of such observations is depicted in column 2). The analogous computations for the relation between the direct channel and Expedia and HRS yielded similar results.

Finding 7: The direct channel price is not larger than the Booking.com price in more than $75 \%$ of the cases

The instances in which the direct channel price is strictly larger than the Booking.com price range from only $16 \%$ in Germany to $33 \%$ in Canada. This confirms our Conjecture 3 that the direct channel price is typically not above the price at an OTA. However, in a significant minority of the cases the direct channel price is higher than the Booking.com price. Such a price differentiation might be profitable for a hotel if it usually encounters customer groups with a higher willingness to pay on the direct channel. An alternative explanation is that - in countries where other OTAs enforce BPCs - the direct channel price is bound by BPCs of other OTAs to be higher than on Booking.com.

\section{Finding 8: The direct channel price is below the Booking.com price in more} than $1 / 3$ of the cases, but least often in Canada - the wide BPC-country in our data set

Across countries there is a remarkably large share of Kayak requests with a direct channel price strictly below the Booking.com price (Table 6). This share is the highest in Sweden (43\%) and Austria (44\%), and the lowest in the wide BPC country Canada (29\%). As in all countries - except of France throughout and Germany for Booking.com and HRS - at least narrow BPCs are in place, this strongly suggests that direct channel prices covered 
by a BPC are nevertheless below the price at Booking.com in a considerable number of cases. This is in contrast to Conjecture 4 and suggests that hotels are non-compliant to the $\mathrm{BPC}$ on a regular basis. Nevertheless, that the violations of the $\mathrm{BPC}$ are least frequent in Canada where the widest form of BPCs is in place indicates that BPCs do have a disciplining effect on (some) hotels.

\section{Finding 9: Compliance of the direct channel parity seems to be higher under the wide BPCs in Canada than with narrow BPCs in Europe}

An additional view on the relation between direct prices and Booking.com prices across different BPC regimes yields the box plot in Figure 2. It shows the distribution of the difference between direct price and the Booking.com price of all Kayak requests that contain prices of both channels. The observations are grouped into the three BPC regimes according to the country of observation, and in the case of Germany also according to the month of observation 25

Figure 2: Relation between Booking.com and direct channel across BPC regimes

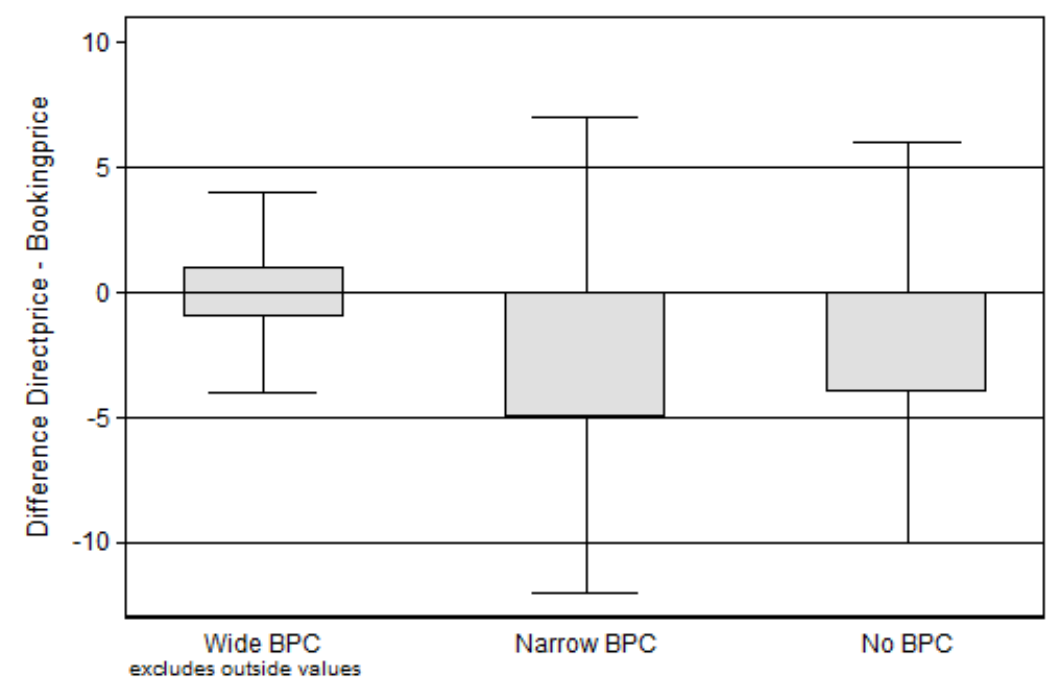

The box plots show that the difference of direct channel and Booking.com most often ranges between \pm 5 EUR and that price dispersion between the direct channel and Booking.com is the lowest under the wide BPC in Canada. The dispersion is considerably higher for the narrow BPC group and the group that is not subject to a BPC.

\footnotetext{
${ }^{25}$ For Germany, the observations from January are assigned to the narrow BPC and all observations from February on are assigned to the group of no BPC which additionally contains France.
} 
This figure confirms that neither under the wide nor narrow BPC full compliance to the price parity can be observed and that compliance is weaker under the narrow BPC than under the wide BPC.

The latter finding is interesting in that one might expect the same compliance in relation to the direct channel price under a narrow and a wide BPC as both restrict the direct channel price not to be lower than the OTA price. The finding of less compliance in case of narrow BPCs might be due to other restrictions that are relaxed in the narrow parity clauses of Booking, such as limited punishments in case of non-compliance; the competition policy cases run against Booking.com might have also weakened to enforcement power of Booking.com in non-contractual ways.

Finding 10: There is a unique price leader across channels in about half of all observations, with an average relative difference to the second price of about $10 \%$

There is a strict price leader in the sense of the second lowest price being strictly higher than the lowest price in $49 \%$ of all Kayak requests with price offers from at least two channels. The frequency of strict price leadership ranges from $40 \%$ in Germany to $60 \%$ in Canada (Table 7, first data column).

For all Kayak requests with offers from at least two channels, Table 7 shows how often a strict minimum price exists and - if it exists - how large the average relative difference between the strict minimum price and the second lowest price is. In most reported countries the relative difference between the minimum price and the second lowest price is on average around 10\%, with a notable exception of $22 \%$ in Italy (second data column). However, in contrast to Conjecture 5, the scope of the BPCs in a country is not related to the frequency of strict price leadership across channels in an obvious way. For instance, in Canada strict price leadership is most frequent although wide BPCs are common, while this share is the lowest in Germany where Booking.com and HRS are not allowed to use BPC anymore, and Expedia only uses a narrow BPC. 
Table 7: Frequency of a unique price leader (strict minimum price) and deviation to second lowest price

\begin{tabular}{lcc}
\hline Country & $\begin{array}{c}\text { Frequency of } \\
\text { unique price } \\
\text { leadership across } \\
\text { channels }\end{array}$ & $\begin{array}{c}\text { Relative difference } \\
\text { to second lowest } \\
\text { price }\end{array}$ \\
\hline \hline Germany & $40 \%$ & $11 \%$ \\
France & $52 \%$ & $10 \%$ \\
Italy & $50 \%$ & $22 \%$ \\
Canada & $60 \%$ & $10 \%$ \\
Sweden & $50 \%$ & $10 \%$ \\
Austria & $53 \%$ & $12 \%$ \\
Others ( neighbor sample) & $59 \%$ & $15 \%$ \\
\hline
\end{tabular}

\section{Discussion: Representativeness of the direct channel observations}

Regarding the representativeness of the findings, recall that direct online prices are only observed in $14 \%$ of all Kayak requests. The direct online channel is likely to be used by a larger fraction of the hotels. It is not guaranteed that the direct channel listing observed on Kayak are fully representative for all hotels with direct online channels. In particular, it could be that larger hotels and chains with better IT capabilities and scale economies are over-represented. It also cannot be excluded that some - potentially larger hotels or hotel chains - have negotiated individual contracts with Booking.com that do not contain parity clauses. For instance, there are large hotel chains in Sweden, and in this country the direct prices are indeed strictly lower than the Booking.com price most of the time, as mentioned above. However, we consider this unlikely to be the main or even only driver of the above observations, but acknowledge that the actual non-compliance frequencies might be slightly different for the whole hotel population.

With respect to the precision of the price relationship statistics, our manual validation exercise we could correctly identify the price leader by means of Kayak data in more than $90 \%$ of the cases (see Subsection 4.3 and Annex II for details). We take this as an indication that Kayak correctly displays price relations across channels most of the times. As a rule of thumb, one could consider $10 \mathrm{pp}$ as a possible margin of error for the bilateral price relationship statistics, i.e. consider a result only as robust when the "null hypothesis" can be rejected by a margin at least 10 pp. Our results are robust in this respect. Moreover, we acknowledge that the existence of a unique price leader might be 
affected to some extent by missing direct channel prices.

\subsection{Effects of Booking.com's removal of the narrow best price clause in Germany on pricing}

\section{Finding 11: The direct channel is increasingly often cheaper than Booking and Expedia in Germany}

We conjecture that the prices at the direct channel and at Expedia are more often lower than at Booking.com after the abolition of Booking.com's narrow BPC in Germany (Conjectures 6 and 7 . In order to test these conjectures, we employ a similar regression analysis as for the price availabilities. Table 8 shows the regressions results on the price relations between Booking.com and the direct channel (column 1, "B>D"), Expedia and the direct channel (column 2, "E>D"), Booking.com and Expedia (column 3, "B>E") and Booking.com and HRS (column 4, "B $>\mathrm{H} ")$.

The dependent variable is equal to 100 if the price in the first channel is strictly above the price in the second channel (e.g., the Booking.com price strictly above the direct channel for column 1), and zero otherwise. We again allow for country-specific time trends to capture whether the price relation changes in Germany following the abolition of Booking.com's narrow BPCs and in how far the time trends in the other countries deviate from the German time trend. We control for the share of non-listed hotels in the city where the hotel is located, the time interval between booking and travel date and include hotel fixed effects. 
Table 8: Price comparison

\begin{tabular}{lcccc}
\hline \hline & $(1)$ & $(2)$ & $(3)$ & $(4)$ \\
& $\mathrm{B}>\mathrm{D}$ & $\mathrm{E}>\mathrm{D}$ & $\mathrm{B}>\mathrm{E}$ & $\mathrm{B}>\mathrm{H}$ \\
\hline Trend (Base: Germany) & $0.85^{* * *}$ & $2.16^{* * *}$ & $-1.33^{* * *}$ & $-1.84^{* * *}$ \\
$\Delta$ Trend France & $-1.11^{* * *}$ & $-1.93^{* * *}$ & $0.78^{* * *}$ & $1.21^{* * *}$ \\
$\Delta$ Trend Italy & $-1.04^{* *}$ & $-2.03^{* * *}$ & $0.57^{* * *}$ & $0.65^{* *}$ \\
$\Delta$ Trend Sweden & $1.40^{* * *}$ & $-2.53^{* * *}$ & $2.63^{* * *}$ & $1.40^{* * *}$ \\
$\Delta$ Trend Austria & $-2.39^{* * *}$ & $-2.49^{* * *}$ & $0.58^{*}$ & $0.89^{* *}$ \\
$\Delta$ Trend Canada & $1.60^{* * *}$ & $-2.23^{* * *}$ & $3.68^{* * *}$ & $4.44^{* * *}$ \\
$\Delta$ Trend Other countries & 0.04 & 0.94 & $1.57^{* * *}$ & $2.19^{* * *}$ \\
Share of non-listed hotels & $-3.36^{* * *}$ & $4.05^{* * *}$ & $-6.02^{* * *}$ & $-12.32^{* * *}$ \\
7 days before & 0.35 & 0.33 & $1.41^{* * *}$ & $-0.36^{*}$ \\
14 days before & 0.22 & $0.39^{*}$ & $-0.30^{* *}$ & $1.25^{* * *}$ \\
21 days before & $1.45^{* * *}$ & 0.09 & $-0.75^{* * *}$ & $1.43^{* * *}$ \\
28 days before & $2.20^{* * *}$ & 0.09 & -0.19 & $2.63^{* * *}$ \\
Hotel FE & Yes & Yes & Yes & Yes \\
Weekdays & Yes & Yes & Yes & Yes \\
\hline Observations & $1,754,006$ & $1,785,838$ & $6,977,803$ & $2,365,892$ \\
$R^{2}$ & 0.004 & 0.006 & 0.005 & 0.007 \\
Adjusted $R^{2}$ & 0.004 & 0.006 & 0.005 & 0.007 \\
Within $R^{2}$ & 0.00 & 0.01 & 0.00 & 0.01 \\
\hline \hline
\end{tabular}

Heteroscedasticity-robust standard errors not reported.

${ }^{*} p<0.1,{ }^{* *} p<0.05,{ }^{* * *} p<0.01$

With respect to conjecture 6, we consider the time trend of the relation between Booking.com and the direct channel (column 1 of Table 8) in Germany. The significant coefficient of $0.85 \mathrm{pp}$ per month confirms that the price at Booking.com is increasingly often above the direct channel price.

The coefficients on the other countries (row 2-7) indicate the deviations from the German trend and, therefore, how the differences between the countries evolve over time. The trends in France, Italy and Austria are significantly less positive, while they are significantly more positive in Sweden and Canada than in Germany. It is an astonishing result that especially in a wide $\mathrm{BPC}$ country like Canada this trend is the strongest in magnitude. It indicates an increasing non-compliance to the BPCs in these countries, or that - potentially large or chained - hotels increasingly agree with Booking.com on terms without parity clauses.

Additionally, we observe in column 2 that the direct channel also becomes more often cheaper than Expedia in Germany - despite that fact that Expedia still imposes a narrow BPC. This shows that the compliance to Expedia's price parity clause decreases more 
and more over time in Germany. As argued already before, in view of the ongoing Bundeskartellamt investigation, it might be that market participants anticipate an abolition for Expedia's BPC in Germany as well and incorporate this into their pricing.

We observe that over time the direct channel offers more often a lower price than Booking.com and Expedia in Germany. Especially the result with respect to Booking.com is in accordance with conjecture 6 that hotels make use of their new price setting freedom after the abolition of a narrow BPC and set lower prices on their direct channel.

We also conjecture that Expedia prices might decrease relative to Booking.com's prices once there is no direct channel parity for Booking.com anymore, but still for Expedia (Conjecture 7). However, note that the coefficient on the relation between Booking.com and Expedia is significantly negative and equals minus 1.33 pp per month (column 3). This regression result suggests that German hotels decided significantly more often to offer lower prices at Booking.com rather than at Expedia.

We reject conjecture 7. Expedia, as the only major OTA in Germany left that still uses narrow BPCs, did not achieve lower prices than Booking.com.

\section{Finding 12: The direct channel is increasingly often the price leader in Ger- many, and Booking.com less often}

According to conjecture 8, the hotels' direct online channel should more often have the lowest price on offer (price leader) following the removal of Booking.com's BPC. Correspondingly, we expect Booking.com to become the price leader less often.

In order to test these conjectures we employ a similar regression analysis as for the price availability. The dependent variable is equal to 100 if the direct channel (first data column) or Booking.com (second data column) has the strictly lowest price on offer, and is 0 otherwise. Anything else is as in the regressions in Table 8. 
Table 9: Channel is price leader (has the strictly lowest price)

\begin{tabular}{lcccc}
\hline \hline & $(1)$ & $(2)$ & $(3)$ & $(4)$ \\
& Direct (str.) & Direct & Booking.com (str.) & Booking.com \\
\hline Trend (Base: Germany) & $0.86^{* * *}$ & $2.72^{* * *}$ & $-0.14^{* *}$ & $0.73^{* * *}$ \\
$\Delta$ Trend France & $-1.60^{* * *}$ & -0.19 & -0.03 & $0.61^{* * *}$ \\
$\Delta$ Trend Italy & $-1.37^{* * *}$ & $-1.62^{* * *}$ & 0.08 & $-0.29^{* * *}$ \\
$\Delta$ Trend Sweden & $-2.29^{* * *}$ & 0.26 & $-0.52^{* * *}$ & $-0.78^{* * *}$ \\
$\Delta$ Trend Austria & -0.78 & -1.14 & $-0.32^{*}$ & 0.06 \\
$\Delta$ Trend Canada & $-0.68^{* * *}$ & $-0.93^{* * *}$ & $-1.13^{* * *}$ & $-1.21^{* * *}$ \\
$\Delta$ Trend Other countries & -0.41 & $-1.12^{* *}$ & -0.04 & $-0.38^{* * *}$ \\
Share of non-listed hotels & $7.06^{* * *}$ & -0.22 & $8.18^{* * *}$ & $9.48^{* * *}$ \\
7 days before & -0.16 & -0.26 & $-1.45^{* * *}$ & $-1.85^{* * *}$ \\
14 days before & -0.14 & $-1.84^{* * *}$ & $-0.76^{* * *}$ & $-1.36^{* * *}$ \\
21 days before & $1.05^{* * *}$ & $1.69^{* * *}$ & $-1.29^{* * *}$ & $-1.36^{* * *}$ \\
28 days before & $1.22^{* * *}$ & $2.10^{* * *}$ & $-1.65^{* * *}$ & $-1.88^{* * *}$ \\
Hotel FE & Yes & Yes & Yes & Yes \\
Weekdays & Yes & Yes & Yes & Yes \\
\hline Observations & $1,958,106$ & $1,958,106$ & $12,046,948$ & $12,046,948$ \\
$R^{2}$ & 0.002 & 0.010 & 0.002 & 0.003 \\
Adjusted $R^{2}$ & 0.002 & 0.010 & 0.002 & 0.003 \\
Within $R^{2}$ & 0.00 & 0.01 & 0.00 & 0.00 \\
\hline \hline
\end{tabular}

Heteroscedasticity-robust standard errors not reported.

${ }^{*} p<0.1,{ }^{* *} p<0.05,{ }^{* * *} p<0.01$

In Germany, the direct online channel is significantly more often the price leader over time (0.86 pp per month, see Table 9, data column 1). For all other countries the coefficients indicating the difference from the German trend are negative, with particularly large and significant values for France, Italy, Sweden, and Canada. For Austria, which as explained before might undergo a similar development as Germany, the coefficient is not significantly different from zero, but the net trend with a value 0.08 nevertheless close to zero.

This is reinforced by the result that the frequency with which Booking.com is the price leader significantly decreases in Germany (minus 0.14 pp per month). Interestingly, Booking.com is also less often the price leader in the other reported countries. This, however, does not contradict the results with respect to the direct channel. It might be the case that another OTA now more often has a cheaper price than Booking.com in these countries. Taken together, the regression results provide a strong indication that the direct channel in Germany is becoming the price leader more often due to the removal of Booking.com's narrow $\mathrm{BPC}$ - in line with Conjecture 8. 


\section{Conclusion}

Motivated by recent proceedings against best price clauses (BPC) imposed by online travel agents (OTA), we empirically investigate the effects of such clauses using meta-search price data of more than 45,000 hotels in various countries. We capture the abolition of Booking.com's narrow BPC during our observation period, so that we are able to particularly address the competitive effects of narrow BPCs.

We have found an increased channel use - both at the intensive and the extensive margin - which can be attributed to the abolition of Booking.com's narrow BPC in Germany. Our difference-in-differences approach also revealed that the hotels are able to establish the direct channel more frequently as the cheaper channel relative to the major OTAs and also more frequently as the price leader in the sense of the cheapest channel across all available online sales channels. This lets us conclude that Booking.com's narrow BPC did indeed restrict the hotel's price setting.

With respect to the price structure across sales channels, we have found that hotels set price at the direct channel lower than at the major OTA in about one third of our observations across all BPC regimes in various countries. This suggests a wide-spread noncompliance with the price parity clause. Nevertheless, the data suggest that especially the wide BPC is to some extent effective in constraining price dispersion across sales channels. We see scope for more empircal research with respect to best price clauses of online travel agents. For instance, there might be major differences in the online sales strategies of different types of hotels such as hotel chains and independent hotels. As a remedy, we used hotel fixed effects in the analysis to accommodate for these factors. Nevertheless, it would be interesting to be able to distinguish the effects of BPC on different types of hotels more explicitly. In addition, we are still investigating the ongoing prohibition processes in other countries such as Austria. Moreover, the theoretical contributions predict anticompetitive effects of $\mathrm{BPC}$ that result in inflated commission rates and eventually retail prices. Although we have not yet observed changes in the standard commission rates of the major OTAs in Europe, future empirical research should take this again into account in order to assess the long term effects and welfare implications of BPCs. 


\section{References}

Boik, Andre and Kenneth S. Corts, "The Effects of Platform Most-Favored-Nation Clauses on Competition and Entry," The Journal of Law and Economics, 2016, 59 (1), $105-134$.

Brynjolfsson, Erik and Michael D. Smith, "Frictionless Commerce? A Comparison of Internet and Conventional Retailers," Management Science, 2000, 46 (4), 563-585.

Buhalis, Dimitrios and Rob Law, "Progress in information technology and tourism management: 20 years on and 10 years after the Internet - The state of eTourism research," Tourism Management, 2008, 29 (4), 609 - 623.

Chellappa, Ramnath K., Raymond G. Sin, and Sivaramakrishna Siddarth, "Price Formats as a Source of Price Dispersion: A Study of Online and Offline Prices in the Domestic U.S. Airline Markets," Information Systems Research, 2011, 22 (1), 83-98.

Clemons, Eric C., Il-Horn Hann, and Lorin M. Hitt, "Price Dispersion and Differentiation in Online Travel: An Empirical Investigation," Management Science, 2002, $48(4), 534-549$.

Edelman, Benjamin G. and Julian Wright, "Price coherence and excessive intermediation," Quarterly Journal of Economics, 2015, 130, 1283-1328.

Ghose, Anindya and Yuliang Yao, "Using Transaction Prices to Re-Examine Price Dispersion in Electronic Markets," Information Systems Research, 2011, 22 (2), 269288.

_ , Panagiotis Ipeirotis, and Beibei Li, "Surviving social media overload: Predicting consumer footprints on product search engines," mimeo, 2012.

Gorodnichenko, Yuriy, Viacheslav Sheremirov, and Oleksandr Talavera, "Price Setting in Online Markets: Does IT Click?," Working Paper 20819, National Bureau of Economic Research December 2014.

Hunold, Matthias, "Best Price Clauses: What Policy as Regards Online Platforms?," Journal of European Competition Law \& Practice, 2016. 
Johnson, Justin P., "The agency model and MFN Clauses," Working Paper, 2014.

Kaplan, Greg, Guido Menzio, Leena Rudanko, and Nicholas Trachter, "Relative Price Dispersion: Evidence and Theory," Working Paper 21931, National Bureau of Economic Research January 2016.

Kracht, John and Youcheng Wang, "Examining the tourism distribution channel: evolution and transformation," International Journal of Contemporary Hospitality Management, 2010, 22 (5), 736-757.

Lu, Qiang, Yupin Yang, and Ulku Yuksel, "The impact of a new online channel: An empirical study," Annals of Tourism Research, 2015, 54, 136 - 155.

Segal, Ilya, "Contracting with Externalities," The Quarterly Journal of Economics, 1999, $114(2), 337-388$.

Stangl, Brigitte, Alessandro Inversini, and Roland Schegg, "Hotels' dependency on online intermediaries and their chosen distribution channel portfolios: Three country insights," International Journal of Hospitality Management, 2016, 52, 87 - 96.

Sun, Sunny, Rob Law, and Tony Tse, "Exploring price fluctuations across different online travel agencies: A case study of room reservations in an upscale hotel in Hong Kong," Journal of Vacation Marketing, 2015.

Ursu, Raluca M., "The Power of Rankings: Quantifying the Effects of Rankings on Online Consumer Search and Choice," Working Paper, 2015.

Wang, Chengsi and Julian Wright, "Search platforms: Showrooming and price parity clauses," Working Paper, 2015.

Wooldridge, Jeffrey M, Econometric analysis of cross section and panel data, MIT press, 2010.

Xiang, Zheng, Vincent P. Magnini, and Daniel R. Fesenmaier, "Information technology and consumer behavior in travel and tourism: Insights from travel planning using the internet," Journal of Retailing and Consumer Services, 2015, 22, 244 - 249. 
Zhao, Kexin, Xia Zhao, and Jing Deng, "Online Price Dispersion Revisited: How Do Transaction Prices Differ from Listing Prices?," Journal of Management Information Systems, 2015, 32 (1), 261-290.

\section{Annex I: Countries and cities covered in data set}

Tables 10 until 14 show the selected countries and cities covered in our data set. Data collection started for the 25 biggest German cities (Table 11) and a control sample of 20 pairs of German and non-German cities along the German border (Table 12) in January 2016. In order to cover all three different BPC regimes in the data and to gather data for countries in which future decisions on BPC are possible, the additional countries depicted in Table 10 were subsequently included. For these countries, we chose a composition of the fifteen biggest cities and fifteen largest travel destinations with the objective to gather representative data across touristic and urban destinations for these countries.

Table 10: Countries covered in data set

\begin{tabular}{ccc}
\hline Country & Cities covered & Start \\
\hline \hline Germany & 25 biggest cities & $25 / 01 / 2016$ \\
Various & 20 pairs of cities near German border & $27 / 01 / 2016$ \\
Italy & 15 biggest cities and 15 tourist destinations & $10 / 02 / 2016$ \\
Sweden & 15 biggest cities and 14 tourist destinations & $12 / 02 / 2016$ \\
Canada & 15 biggest cities and 15 tourist destinations & $12 / 02 / 2016$ \\
France & 15 biggest cities and 15 tourist destinations & $18 / 02 / 2016$ \\
Austria & 15 biggest cities and 15 tourist destinations & $20 / 04 / 2016$ \\
\hline
\end{tabular}

Table 11: Germany - TOP 25 cities

\begin{tabular}{ccccc}
\hline \multicolumn{5}{c}{ Germany TOP 25 cities } \\
\hline \hline Berlin & Stuttgart & Leipzig & Bochum & Karlsruhe \\
Hamburg & Dusseldorf & Dresden & Wuppertal & Mannheim \\
Munich & Dortmund & Hanover & Bielefeld & Augsburg \\
Cologne & Essen & Nuremberg & Bonn & Wiesbaden \\
Frankfurt am Main & Bremen & Duisburg & Munster & Gelsenkirchen \\
\hline
\end{tabular}


Table 12: Twin cities along German border

\begin{tabular}{cccc}
\hline Pair & German City & Non-German neighbor & Country of neighbor \\
\hline \hline 1 & Flensburg & Kolding & Denmark \\
2 & Puttgarden/Fehmarn & Rodby & Denmark \\
3 & Wilhelshaven & Groningen & The Netherlands \\
4 & Borkum & Schiermonnikoog & The Netherlands \\
5 & Rheine & Enschede & The Netherlands \\
6 & Aachen & Maastricht & The Netherlands \\
7 & Heringsdorf & Wolin & Poland \\
8 & Greifswald & Stettin & Poland \\
9 & Cottbus & Zielona-Gora & Poland \\
10 & Trier & Rosport & Luxembourg \\
11 & Monschau & Eupen & Belgium \\
12 & Prüm & St. Vith & Belgium \\
13 & Saarbrücken & Metz & France \\
14 & Karlsruhe & Strasbourg & France \\
15 & Freiburg & Basel & Switzerland \\
16 & Konstanz & St. Gall & Switzerland \\
17 & Oberstdorf & Bad Ischl & Austria \\
18 & Garmisch-Partenkirchen & Innsbruck & Austria \\
19 & Nuremberg & Pilsen & Czech Republic \\
20 & Dresden & Prague & Czech Republic \\
\hline
\end{tabular}


Table 13: Cities covered in data set

\begin{tabular}{|c|c|c|c|c|}
\hline Italy & Canada & France & Sweden & Austria \\
\hline \multicolumn{5}{|c|}{ Biggest Cities } \\
\hline Rome & Toronto & Paris & Stockholm & Vienna \\
\hline Milan & Montreal & Marseille & Göteborg & Graz \\
\hline Naples & Vancouver & Lyon & Malmö & $\operatorname{Linz}$ \\
\hline Turin & Calgary & Toulouse & Uppsala & Salzburg \\
\hline Palermo & Edmonton & Nice & Västeras & Innsbruck \\
\hline Genoa & Ottawa & Nantes & Örebro & Klagenfurt \\
\hline Bologna & Québec & Strasbourg & Linköping & Villach \\
\hline Florence & Winnipeg & Montpellier & Helsingborg & Wels \\
\hline Bari & Hamilton & Bordeaux & Jönköping & St. Pölten \\
\hline Catania & Kitchener & Lille & Norrköping & Dornbirn \\
\hline Venice & London & Rennes & Lund & Wiener Neustadt \\
\hline Verona & Victoria & Reims & Umea & Steyr \\
\hline Messina & Saint Catharines & Le Havre & Gävle & Feldkirch \\
\hline Padua & Halifax & Saint-Étienne & Boras & Bregenz \\
\hline Trieste & Oshawa & Toulon & Eskilstuna & Leonding \\
\hline \multicolumn{5}{|c|}{ Tourist Destinations } \\
\hline Lecce & Regina & Grenoble & Växjö & Zell am See \\
\hline Viareggio & St. John's & Cannes & Lulea & Kitzbühel \\
\hline Matera & Fredericton & Chambéry & Falun & Bad Hofgastein \\
\hline Sanremo & Charlotte Town & Annecy & Varberg & Hermagor \\
\hline Mantova & Whitehorse & Aix-les-Bains & Visby & Schladming \\
\hline Vasto & Yellowknife & Menton & Ystad & Mittelberg \\
\hline Merano & Niagara On The Lake & Albertville & Kiruna & Neustift \\
\hline Caltagirone & Whistler & Bayeux & Strömstad & Bad Gastein \\
\hline Montecatini & Banff & Argelès-sur-Mer & Ronneby & Velden am Wörther \\
\hline Terme & & & & See \\
\hline Narni & Jasper & Chamonix & Jokkmokk & $\begin{array}{l}\text { Finkenstein am } \\
\text { Faaker See }\end{array}$ \\
\hline Abano Terme & Tofino & Évian-les-Bains & Grebbestad & Kirchberg in Tirol \\
\hline Ischia & Dawson City & $\begin{array}{l}\text { Cavalaire-sur- } \\
\text { Mer }\end{array}$ & Marstrand & St. Kanzian \\
\hline Monte Argentario & Churchill & $\begin{array}{l}\text { Saint-Gervais- } \\
\text { les-Bains }\end{array}$ & Jukkasjärvi & Mayrhofen \\
\hline San Felice Circeo & Bay of Fundy & Gruissan & Stöllet & Seefeld in Tirol \\
\hline $\begin{array}{c}\text { Santa Margherita } \\
\text { Ligure }\end{array}$ & $\begin{array}{l}\text { Thousand Islands } \\
\text { National Park }\end{array}$ & Sainte-Marine & & Sölden \\
\hline
\end{tabular}

\section{Selection of travel destinations}

For Italy, Sweden, Canada, France and Austria we selected the travel destinations in two steps. First, we looked up the fifteen biggest cities in terms of population on Wikipedia respectively. Additionally, for each country, we collected information about popular tourist destinations from travel guides and official tourism websites. We then ordered all these destinations by population and took again the fifteen biggest locations. For Italy, France, 
Sweden and Canada the websites were all accessed in January and February 2016. The Austrian cities were selected in April 2016 after the Austrian NCA announced to proceed against the narrow BPC later in 2016.

The sources of the travel destinations can be found in the following table:

Table 14: Sources for travel destination selection

\begin{tabular}{lll}
\hline Country & Type & Source \\
\hline \hline Italy & Listing of health resorts & wikipedia.de \\
& Ten most popular beaches & telegraph.co.uk \\
& Beyond Rome and Florence: 12 & cnn.com \\
& alternative Italian destinations & \\
\hline Sweden & Top 10 Places in Sweden & neverstoptraveling.com \\
& Top 10 Green Attractions & visitsweden.com \\
\hline Canada & Travelers Choice & tripadvisor.com \\
& Tourist attractions & planetware.com \\
& Places to Go & de-keepexploring.canada.travel \\
\hline France & The top 10 beach holidays & telegraph.co.uk \\
& Travelers Choice Destinations & tripadvisor.com \\
& 16 Top-Rated Tourist Attractions in & planetware.com \\
& the French Alps & \\
\hline Austria & Most popular winter destinations & austriatourism.at \\
& Most popular summer destinations & austriatourism.at \\
\hline
\end{tabular}

\section{Annex II: Validation of Kayak data}

As mentioned in 4.3, to validate the accuracy of the offers listed on Kayak we have compared prices and qualitative features of 171 hotels on Kayak with corresponding offers on the websites of the major OTAs and the hotel websites.

We generated our validation sample as follows. From all hotels that we observed in our data we took a random draw of 115 hotels. We augmented the sample with 58 hotels from Germany, Austria and Sweden that we observed to frequently offer a direct sales channel on Kayak. We did this to obtain more observations with direct channel prices as well as HRS prices and to have a better coverage of the countries Germany, Austria and Sweden. Consequently, the sample consists of observations from Canada, Italy, Sweden, Germany, Austria and France plus a few observations for the Czech Republic, Switzerland and Poland. For 40 hotels of our sample Kayak did not display any information during 
the enquiry period for various travel dates.

From a request on Kayak we obtain room rates for all available sales channels and information on room features (e.g. double bed) and booking conditions (e.g. free cancellation, free breakfast, etc.). We used the forwarding links on the Kayak website to reach the corresponding offer on the OTAs and the hotel websites. With the gathered data we conducted two kinds of consistency validations. First, we compare prices and qualitative characteristics of a room offer on Kayak with the corresponding offer on the OTAs or on the hotel website. Second, we verify whether the price structure between the major OTAs and the direct sales channel shown on Kayak is consistent with the price structure on OTAs and hotel websites. In eight cases on Kayak the qualitative features differed across the sales channels. As prices are not comparable across channels in these cases, the observations are excluded from the analysis of the price structure.

As shown in Table 15 we observe that prices coincide in more than two-thirds of all observations on both sources. For this comparison we have assumed that prices coincide if the difference amounts to less than three EUR in order to capture differences in rounding and exchange rates ${ }^{26}$ For deviating prices, the data suggest that prices on Kayak most often are higher than the prices on OTAs and websites and that only in a few cases prices on Kayak are lower than on the actual sales channel. Interestingly, the sales channel that is measured most accurately is the direct sales channel. On average, prices on Kayak and prices on the OTAs or the hotel websites deviate from each other by approximately five EUR. Comparing the room features and booking conditions on both sources, we found that this information on Kayak is identical with the information provided on the OTA or the hotel website, whenever rooms were available on both sources.

Table 15: Frequency of price deviations of Kayak from OTAs and hotel websites

\begin{tabular}{lcccc}
\hline & $\mathrm{N}$ & $\begin{array}{c}\text { Kayak price } \\
\text { higher }\end{array}$ & $\begin{array}{c}\text { Kayak price } \\
\text { equal }\end{array}$ & $\begin{array}{c}\text { Kayak price } \\
\text { lower }\end{array}$ \\
\hline \hline Booking.com & 106 & $26 \%$ & $69 \%$ & $5 \%$ \\
Expedia & 64 & $34 \%$ & $66 \%$ & $0 \%$ \\
HRS & 34 & $29 \%$ & $68 \%$ & $3 \%$ \\
Direct channel & 51 & $12 \%$ & $80 \%$ & $8 \%$ \\
\hline
\end{tabular}

\footnotetext{
${ }^{26}$ Expedia displays an exact amount including euros and cents for a hotel room, while Booking.com usually adjusts prices upwards to the next integer. Moreover, prices from Sweden or Canada sometimes were displayed in domestic currencies. For the sake of comparability, we converted the prices in EUR using the exchange rate of the booking date (Source: www.finanzen.net/waehrungsrechner/).
} 
However, in some cases Kayak displayed for a certain hotel on a certain sales channel more than one available combination of room features and booking conditions ${ }^{27}$ In order to ensure comparability among sales channels in the second consistency validation, we only compared hotel offers of different sales channels with each other if these offers were qualitatively identical. In more than $90 \%$ the offers on all sales channels were qualitatively identical regarding room features and booking conditions. Among these offers we identify a price leadership whenever the lowest price is at least 1 EUR lower than the second lowest price. Table 16 shows that the information whether one sales channel is the price leader (i.e. offers a price strictly lower than the second best and qualitatively identical offer) is consistent between Kayak and the actual sales channels in approximately $90 \%$. If there is a distinct price leader the average difference between the lowest price and the second lowest price is around 7.50 EUR both on Kayak and on the sales channels.

Table 16: Consistency of price leadership

\begin{tabular}{lcc}
\hline Price leadership & N & Price leadership consistent \\
\hline \hline Booking.com & 67 & $91 \%$ \\
Expedia & 54 & $92 \%$ \\
HRS & 26 & $90 \%$ \\
Direct channel & 34 & $85 \%$ \\
\hline
\end{tabular}

\section{Annex III: Evidence on commission rates of OTAs}

We understand that major OTAs such as Booking.com and Expedia use an agency model where hotels set room prices on the OTA and pay a commission to the OTA for every realized booking via the OTA. We understand that effective commissions are determined by a standard rate plus an additional fee if hotels want to appear higher in the OTA's ranking. ${ }^{28}$ The interventions against BPCs aimed at removing restraints of competition among OTAs in commission rates. However, the recent interventions have not obviously

\footnotetext{
${ }^{27}$ E.g. It is possible that Kayak indicated that on Booking.com there is one standard double room with free breakfast for 100 EUR and that there is on superior double room without breakfast for 110 EUR. For the same hotel request on Kayak it also is possible that Expedia only has the superior room without breakfast on offer. We then compared the superior room across channels.

${ }^{28}$ For example via Expedia's hotel accelerator program that sells higher ranking positions by auction (see https://skift.com/2016/03/03/first-look-at-expedias-hotel-accelerator-program-for-improving-hotelplacement/; last accessed 25 September, 2016) or Booking.com's preferred partner program (see http://www.booking.com/content/hotel-help.de.html, last accessed 25 September, 2016).
} 
led to significant changes in the OTAs' commission rates so far. A recent ${ }^{29}$ Europe-wide survey among more than 2,000 hoteliers by HOTREC finds that for more than $90 \%$ of all hotels the effective commission rates have not decreased over the past one year 30

Our anecdotal examination (including interviews with hoteliers) in the course of 2016 indicates that basis commission rates of the major OTAs range between $12 \%$ and $18 \%$ in Europe. While we took note of basis commissions of $15 \%$ at Expedia and HRS, Booking.com's basis commissions apparently vary across destinations (see Table 17 for the observations). Similarily, the Bundeskartellamt reported in the decisions regarding HRS 31 and Booking.com ${ }^{32}$ that in 2013 and in 2015 the major OTAs' basis commission rates range from $10 \%$ to $15 \%$. This also indicates that in Germany (basis) commissions have not changed in the last years.

Table 17: Booking.com's standard commissions by destination

\begin{tabular}{cccccccc}
\hline Düsseldorf & Berlin & Termoli & Rome & Örebro & Stockholm & Toulouse & Paris \\
\hline $12 \%$ & $15 \%$ & $15 \%$ & $18 \%$ & $15 \%$ & $15 \%$ & $17 \%$ & $15 \%$ \\
\hline
\end{tabular}

According to the Bundeskartellamt, effective commissions can account for up to $50 \%$ of the room price. ${ }^{33}$ In 2015, the German hotel association estimated average commissions payments to range between $20 \%$ and $25 \% .34$

\footnotetext{
${ }^{29} \mathrm{HOTREC}$ is the European trade association of hotels, restaurants and cafes in Europe.

${ }^{30}$ HOTREC survey on online platforms of 2016 (see http://www.hotrec.eu/newsroom/press-releases1714/dominant-online-platforms-gaining-market-share-in-travel-trade-no-signs-of-increased-competitionbetween-online-travel-agents-unveils-european-hotel-distribution-study.aspx; last accessed 03 September, 2016).

${ }^{31}$ Bundeskartellamt (2013) B9-66-10 Par. 225

${ }^{32}$ Bundeskartellamt (2015) B9-121-13 Par. 18.

${ }^{33}$ Bundeskartellamt (2015) B9-121-13 Par. 2.

${ }^{34}$ Statement of the German hotel association from August 31, 2015 according to Bundeskartellamt (2015) B9-121-13, Fn 414.
} 


\section{Annex IV: Public decisions with respect to BPCs of OTAs in Europe}

Table 18: List of public decisions with respect to BPCs

\begin{tabular}{|c|c|c|c|c|}
\hline Date & Country & $\begin{array}{l}\text { Decision } \\
\text { body }\end{array}$ & Content & Reference \\
\hline $01 / 2014$ & UK & OFT & OFT decision & $\begin{array}{c}\text { Decision } 31.01 .2014, \text { OFT1514dec - } \\
\text { Case reference CE/9320/10 }\end{array}$ \\
\hline $12 / 2013$ & Germany & $\begin{array}{l}\text { Bundes- } \\
\text { kartellamt }\end{array}$ & Prohibition & $\begin{array}{l}\text { Decision of } 20.12 .2013, \text { B } 9-66 / 10 \\
\text { - HRS - Hotel Reservation Service }\end{array}$ \\
\hline $04 / 2015$ & Sweden & $\begin{array}{l}\text { Konkurrens- } \\
\text { verket }\end{array}$ & $\begin{array}{c}\text { Acceptance of } \\
\text { Booking.com's } \\
\text { commitment to at most } \\
\text { narrow BPCs with effect } \\
\text { of July } 2015\end{array}$ & $\begin{array}{c}\text { Decision of } 15.04 .2015-596 / 2013- \\
\text { Booking.com }\end{array}$ \\
\hline$"$ & France & $\begin{array}{l}\text { Autorité de la } \\
\text { concurrence }\end{array}$ & $"$ & $\begin{array}{c}\text { Decision of } 21.04 .2015-15-\mathrm{D}-06- \\
\text { Booking.com }\end{array}$ \\
\hline$"$ & Italy & $\begin{array}{c}\text { Autorità } \\
\text { Garante della } \\
\text { Concorrenza e } \\
\text { del Mercato }\end{array}$ & " & $\begin{array}{c}\text { Decision of } 21.04 .2015-\text { I779 - } \\
\text { Booking.com }\end{array}$ \\
\hline 2015 & UK & Court decision & $\begin{array}{c}\text { OFT decision was } \\
\text { annulled on appeal on } \\
\text { procedural grounds }\end{array}$ & $\begin{array}{l}\text { CMA press release, } 16.09 .2015, \\
\text { CMA closes hotel online booking } \\
\text { investigation }{ }^{a}\end{array}$ \\
\hline $07 / 2015$ & EU/EEA & Expedia & $\begin{array}{l}\text { Announces to use narrow } \\
\text { BPCs in Europe }\end{array}$ & $\begin{array}{l}\text { Expedia press release 01.07.2015; } \\
\text { „Expedia Amends Rate, Conditions } \\
\text { and Availability Parity Clauses". }{ }^{b}\end{array}$ \\
\hline $07 / 2015$ & France & $\begin{array}{c}\text { French } \\
\text { parliament }\end{array}$ & $\begin{array}{l}\text { Law that prohibits BPCs } \\
\text { for OTAs in France }\end{array}$ & „Loi Macron“ 10.07.2015.c \\
\hline $12 / 2015$ & Germany & $\begin{array}{c}\text { Bundes- } \\
\text { kartellamt }\end{array}$ & $\begin{array}{c}\text { Prohibitions of } \\
\text { Booking.com's narrow } \\
\text { BPCs by February } 2016 . \\
\text { Announcement to } \\
\text { continue investigation } \\
\text { with Expedia }\end{array}$ & $\begin{array}{l}\text { Bundeskartellamt, decision of } \\
\text { 23.12.2015, B 9-121/13-- } \\
\text { Booking.com. }\end{array}$ \\
\hline
\end{tabular}

Government bill to prohibit narrow BPCs for

07/2016 Austria Ministerrat OTAs in Austria. To be Government bill (1251 d.B.) adopted in the course of 2016

${ }^{a}$ See https://www.gov.uk/government/news/cma-closes-hotel-online-booking-investigation (last access 11.04.2016)

${ }^{b}$ See http://www.expediainc.com/news-release/?aid=123242\&fid=99\&yy=2015, last access 11.04.2016.

${ }^{c}$ See http://www.hotelnewsnow.com/Article/16460/Frances-end-to-rate-parity-creates-grey-areas for more information, last access 27.04.2016. 


\section{Annex V: Definition of OTAs and direct sales channels}

In our data set, we observe 73 distinct sales channels that list hotel rooms on Kayak. These can be classified into OTAs like Booking.com, and the direct hotel channel. Taking together all hotel offers out of all Kayak requests, we observe in total more than 66 million price offers. Table 19 lists the 15 most observed sales channels that account for almost $90 \%$ of all observed price offers. Booking.com is the most frequent channel in our data set accounting for almost $20 \%$ of all price observations.

Table 19: Sales channels observed on Kayak

\begin{tabular}{lcc}
\hline \hline Sales Channel & No. & $\%$ \\
\hline BOOKINGDOTCOM & 12887457 & 19.5 \\
HOTELSDOTCOM & 9136874 & 13.8 \\
EXPEDIAHOTEL & 9085679 & 13.7 \\
HOTELRESERVIERUNG & 4319986 & 6.5 \\
EBOOKERSHOTEL & 4313642 & 6.5 \\
AGODA & 3311827 & 5.0 \\
HRS & 3301302 & 5.0 \\
HOTELOPIA & 2152581 & 3.3 \\
AMOMA & 2082432 & 3.1 \\
HOTELSCLICK & 2034302 & 3.1 \\
OTEL & 1519277 & 2.3 \\
LOWCOSTHOLIDAYS & 1362477 & 2.1 \\
VENERE & 1106848 & 1.7 \\
HOTELTRAVEL & 905966 & 1.4 \\
PWOPODOHOTEL & 676716 & 1.0 \\
Total & 66137388 & 100.0 \\
\hline \hline
\end{tabular}

It is noteworthy that the well known OTAs Booking.com, Expedia and HRS belong to company groups which own further OTAs (Table 22). Together the three company groups account for almost $2 / 3$ of our price observations. For these Kayak requests in which two OTAs of the same company group are observed together (column 4), we computed how often the prices are identical (column 5).

As a benchmark, we also compared the primary OTAs Booking.com, Expedia and HRS in Tables 20 and 21. Table 20 shows how frequently the OTAs appear together in one Kayak request. For those Kayak requests in which two OTAs are observed together, we find that prices are equal in less than $50 \%$ (Table 21). 
Table 20: Contingency of OTA Listings

\begin{tabular}{lccc}
\hline & Booking.com & Expedia & HRS \\
\hline \hline Booking.com & $12,887,457$ & & \\
Expedia & $7,451,659$ & $9,085,679$ & \\
HRS & $2,772,150$ & $2,597,228$ & $3,301,302$ \\
\hline
\end{tabular}

Table 21: Price coherence on major OTAs

\begin{tabular}{lccc}
\hline & Booking.com & Expedia & HRS \\
\hline \hline Booking.com & $100 \%$ & & \\
Expedia & $42 \%$ & $100 \%$ & \\
HRS & $51 \%$ & $48 \%$ & $100 \%$ \\
\hline
\end{tabular}

We conducted the same analysis with OTAs belonging to the same company group. The OTA Agoda that belongs to the Priceline Group appears in more than $80 \%$ with the primary website Booking.com. For the OTAs belonging to Expedia Inc. (Hotels.com, Venere, ebookers) the mutual appearance with the primary website Expedia is at almost $100 \%$ of all observations. The Expedia website prices are also very often equal to the prices at Hotels.com and Venere 35 which suggests to treat them as one entity. For ebookers a abrupt change in pricing policy can be observed between May and June 2016. While ebookers used to have a price parity with Expedia in only $18 \%$ of all Kayak requests until May, this value increased in June and July to 90\%. Therefore, also Expedia and ebookers is treated as one entity.

Interestingly, the correspondence between Booking.com and Agoda is quite low. As a consequence, we treat them as separate OTAs. Finally, we also treat HRS and Hotel.de as separate as the mutual appearance between HRS and Hotel.de is at only $44 \%$ and also the coherence is only moderate and Hotel.de is quite small with only $1 \%$ of all price listings.

\footnotetext{
${ }^{35}$ Note that the OTA Venere is observed on Kayak only in January and February 2016.
} 
Table 22: Price coherence within company groups

\begin{tabular}{lcccc}
\hline Group & OTA & $\begin{array}{c}\text { Share in total } \\
\text { price listings }\end{array}$ & $\begin{array}{c}\text { Appearance } \\
\text { with primary } \\
\text { website }\end{array}$ & $\begin{array}{c}\text { Price coherence } \\
\text { with primary } \\
\text { website }\end{array}$ \\
\hline \hline \multirow{2}{*}{ Priceline } & Booking.com & $19 \%$ & $100 \%$ & $100 \%$ \\
& Agoda & $5 \%$ & $84 \%$ & $39 \%$ \\
\hline \multirow{2}{*}{ Expedia Inc. } & Expedia & $14 \%$ & $100 \%$ & $100 \%$ \\
& Hotels.com & $14 \%$ & $98 \%$ & $92 \%$ \\
& Venere & $2 \%$ & $98 \%$ & $98 \%$ \\
HRS Robert & ebookers & $5 \%$ & $95 \%$ & $50 \%$ \\
Ragge GmbH & HRS & $5 \%$ & $100 \%$ & $100 \%$ \\
\hline
\end{tabular}

\section{Annex VI: Increase of Booking.com's listing frequency}

\section{in Germany - robustness check}

As argued in subsection 6, the interpretation of the analysis of the listing decisions suggests that there is distinctive increase in Booking.com's listing frequencies that can be attributed to the abolition of Booking.com's narrow BPC early in 2016. Alternatively, Booking.com might undergo a general catch-up process in regions where it is is less established.

However, to descriptively verify the robustness of this result, we conducted a comparison between the evolvement of Booking.com's listing frequency in Germany and in a control group. The control group comprises of nine non-German cities that, on average, exhibit the same frequency Booking.com listing frequency as it can be observed in Germany at the beginning of 2016. The cities of the control group were selected as follows:

At the city level, we computed for every month the average Booking.com frequency. Taking the nine non-German cities with the lowest Booking.com frequency in February yields approximately the same average Booking.com frequency as for Germany as a whole (74.5\%, while $72.6 \%$ in Germany). These cities are Rome, Venice, Ischia (all Italy), Rodby (Denmark), Dawson City, Yellowknife, Gananoque (Ottawa), Tofino, St. Catharines (all Canada). Figure 3 shows how Booking.com frequencies evolve over time for the two groups. As seen in subsection 6, in Germany the frequency increases sharply from $73 \%$ 
in February to $96 \%$ in June and July. The listing frequency of the control sample has the same frequency level at the beginning of the year. But in contrast to Germany, the control sample increases only slightly until May to a frequency of $77.6 \%$ and shows a decreasing trend from then on ending up even below the February level at $73.7 \%$ in July.

Hence, we conclude from the comparison of Germany with a control sample consisting of nine cities from Europe and Canada that there is no general catch-up process in regions with low Booking.com frequencies that drives the development in Germany. In turn, this result is taken as supporting evidence that the abolition of Booking.com's BPCs in Germany can be contributed to the especially sharp increase of Booking.com listings in Germany.

Figure 3: Booking.com Frequency (Germany and control group)

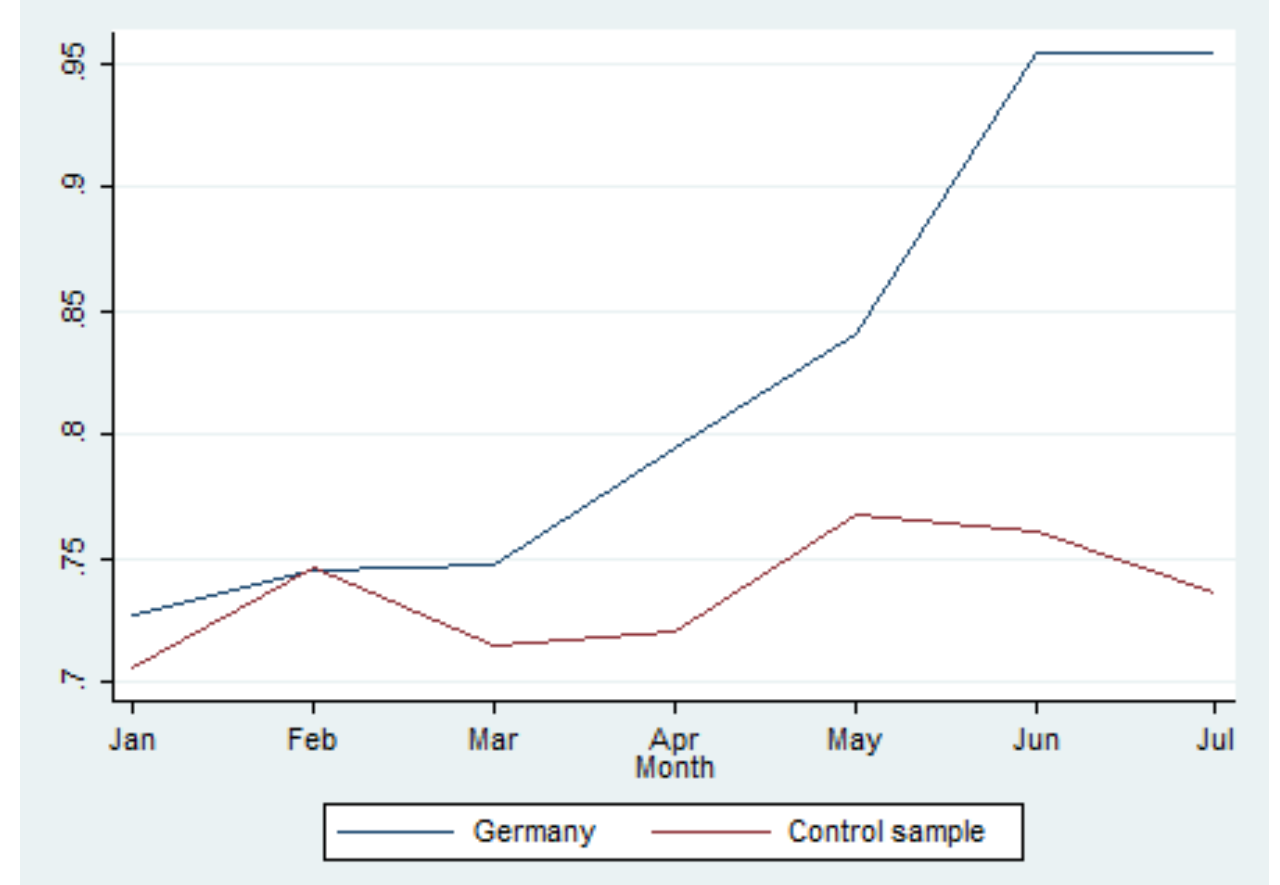

